\title{
Effect of spark location and laminar flame speed on the ignition transient of a premixed annular combustor
}

\author{
Roberto Ciardiello $^{\mathrm{a}, *}$, Pedro M. de Oliveira ${ }^{\mathrm{a}}$, Aaron W. Skiba ${ }^{\mathrm{a}}$, Epaminondas Mastorakos $^{\mathrm{a}}$, Patton M. Allison ${ }^{\mathrm{b}}$ \\ ${ }^{a}$ Department of Engineering, University of Cambridge, Cambridge, UK \\ ${ }^{b}$ Department of Mechanical engineering, Michigan State University, East Lansing, MI USA
}

\begin{abstract}
The flame expansion process ("light-round") during the ignition transient in annular combustors depends on a number of parameters such as equivalence ratio (and hence laminar burning velocity, $S_{L}$, of the mixture), turbulent intensity, mean flow magnitude and direction, geometry, and spark location. Here, an experimental study on a fully premixed, swirled, bluff-body stabilised annular combustor is carried out to identify the sensitivity of the light-round to these parameters. A wide range of conditions were assessed: two inter-burner spacing distances, two fuels (methane and ethylene), bulk velocities from 10 to $30 \mathrm{~m} / \mathrm{s}$, and $\phi$ between 0.75 and 1 for methane and 0.58 and 0.9 for ethylene. The spark location was varied longitudinally $(x / D=0.5$ and $x / D=5$, where $D$ is the bluff body diameter, expected to lie inside and downstream of the inner recirculation zone of a single burner, respectively) and azimuthally. The propagation of the flame during the ignition transient was investigated via high speed $(10 \mathrm{kHz}) \mathrm{OH}^{*}$ chemiluminescence using two cameras to simultaneously image the annular chamber from axially downstream and from the side of the combustor. The pattern of flame propagation depended on the initial longitudinal spark location and comprised of burner-to-burner propagation close to the bluff bodies and upstream propagation of the flame front. The spark azimuthal position, in this horizontal configuration, had a negligible impact on the light-round time $\left(\tau_{L R}\right)$, thus buoyancy plays a minor role in the process. In contrast, sparking at $x / D=5$ resulted in an increase in $\tau_{L R}$ by $\sim 30-40 \%$ for all the conditions examined. The inter-burner spacing had a negligible effect on $\tau_{L R}$. When increasing bulk velocity, $\tau_{L R}$ decreased. For a constant bulk velocity, $\tau_{L R}$ depended strongly on $S_{L}$ and it was found that mixtures with the same $S_{L}$ from different fuels resulted in the same $\tau_{L R}$. Further, the observed propagation speed, corrected for dilatation, was approximately proportional to $S_{L}$ and was within $30 \%$ of estimates of the turbulent flame speed at the same conditions. These findings suggest that $S_{L}$ is one of the controlling parameters of the light-round process; hence turbulent flame propagation has a major role in the light-round process, in addition to dilatation and flame advection by the mean flow. The results reported in the study help explain the mechanism of light-round and can assist the development of efficient ignition procedures in aviation gas turbines.
\end{abstract}

Keywords: Annular combustor, Light-round, Spark ignition, Turbulent premixed flames, Ignition time

\section{Introduction}

Lean premixed combustion is a promising candidate for reducing emissions of harmful pollutants in aerothermal propulsion $[1,2]$ and ground-based power production [3]. The drawbacks are a reduction of the operating range of the engines and the possibility of detrimental phenomena in the combustion chamber, namely thermoacoustic instabilities and lean blow-off. Consequently, a major concern in the design stage of the

\footnotetext{
${ }^{*}$ Corresponding author

Email address: rc733@cam.ac.uk (Roberto Ciardiello)
}

combustor is the relight and stabilisation of the flame. In addition, as these engines need to be most resilient during take-off, they may not be optimised for being efficient during the ignition stage at ground level. This is also relevant for stationary gas turbines, that need to be reliable and stable with an increasing number of fuels and operating conditions [3]. Thus, a deep understanding of the mechanism of the ignition process of gas turbine combustors and how flow and mixture characteristics control the process is required.

In gas turbine combustors, ignition is usually achieved by using surface discharge igniters to locally deliver the energy to initiate the process (forced 
ignition)[4]. The ignition transient can be divided in four phases $[5,6]$. Phase one is the formation and establishment of a flame kernel due to the quick rise in temperature in the region surrounding the spark. Then, second phase, the flame kernel grows into a self-sustained flame, propagating towards the fresh reactants. The third phase is the establishment of the flame on a single burner, which depends on the burner geometry and the stabilisation device (i.e. swirl or bluff body) in addition to the mean flow that may convect the flame toward the anchoring region or away from it. In multiburner configurations [1] there is a fourth phase of the ignition process: the burner-to-burner propagation until complete stabilisation of the flame in the entire combustor. This phenomenon is known as light-round.

The ignition transient in single burner setups has been widely experimentally investigated in premixed, nonpremixed, and spray configurations with different geometries [7-16]. However, gas turbine combustors usually employ geometries comprising multiple burners. Therefore, the light-round process becomes crucial for the successful ignition of the combustor. The mechanism of burner-to-burner propagation of the flame can be significantly different from the stabilisation over a single burner. Moreover, it is affected by the local flow conditions inside the chamber. In particular, flame propagation is competing with the flow velocity and depends on the probability of finding flammable mixture inside the chamber, a condition that strongly differs between non-premixed and premixed systems. Thus, studies of ignition within more complex geometries are necessary to increase understanding of the ignition process in gas turbine combustors.

In previous works, non-premixed and spray burners were employed in linear [17-19] and full annular configurations [20-24] for the study of the light-round phenomenon. In a non-premixed mode, where the combustion chamber is not evenly filled with a flammable mixture, it was found that propagation depended on the likelihood that an inner recirculation zone (IRZ) of a single burner could capture flame fragments from an adjacent burner already lit [21], consistent with the single-burner studies in Refs. $[12,14]$. The process was found to be stochastic in nature due to the mixture fraction distribution and local strain effects. The flammability factor (defined as the probability to find flammable mixture in a certain region) was highest in the IRZ in the mixing layer between the fuel jet and the air stream. In the inter-burner region, bridges of positive (i.e. greater than zero) flammability factor were detected, due to the entrainment of fuel in the air flow and to the interaction between adjacent burners [19]. In a linear configura- tion [17], it was reported that increasing the separation distance between adjacent burners resulted in a switch from a span-wise propagation pattern (characterised by high light-round speed and low variability) to an axial mode (characterised by lower light-round speed, higher variability and even ignition failures). This was attributed to an aerodynamic separation of the streams from adjacent burners, leading to very lean mixtures in the inter-burner region [18]. Large Eddy Simulations (LES) performed on this linear configuration by Barré et al. [17] reported the same shift in propagation pattern. In addition, the flame front was tracked using a progress variable and the relative contribution of flame displacement speed and bulk flow to the flame propagation speed was evaluated, depending on the separation distance. Their results indicate that increasing the separation distance strongly affected the bulk flow contribution, with a minor change in flame displacement speed, explaining the experimental evidence of increase in light-round time with separation distance [17].

In spray configurations, fuel vaporisation affected single burner ignition as well as flame propagation across the chamber [20]. The light-round speed was lower, due to the decrease in flame speed associated with the droplet evaporation, even though the propagation mechanism was similar to that of gaseous mixtures. The light-round time decreased when increasing the thermal power, bulk velocity, or the equivalence ratio of the mixture [22]. Propagation near the injectors was found to be mainly azimuthal, while the flame front in the region downstream of the burners propagated axially and azimuthally, due to the gaseous expansion [23, 24]. LES performed by Puggelli et al. [25] highlighted the impact of wall temperature and heat losses on the light-round propagation. Imposing adiabatic conditions at the walls [23] could be an oversimplification of the phenomenon, while a more complex modelling of wall temperature and heat flux is needed to better capture the process [25].

For fully premixed systems, the flame propagation is facilitated by the presence of a uniform combustible mixture inside the chamber. From the initial spark, two flame branches are formed, which sweep across the annular chamber to ignite each burner. The mechanism of light-round was found to comprise of two parts: (i) flame propagation from one burner to its neighbour, and (ii) succession of upstream movements of the flame front to ignite each individual burner, leading to a sort of "sawtooth" pattern [26-28]. In addition, the light-round time was found to decrease when increasing mixture velocity and equivalence ratio [26, 27] or when reducing the inter-burner distance [27]. Bourgouin et al. [26] pro- 
posed a theoretical interpretation of the results, based on a G-equation framework that treated the flame as a discontinuity between fresh and burnt reactants. The flame front propagation was assumed to be a combination of: (i) axial and azimuthal flow velocities encompassing effects of gaseous expansion $\left(\rho_{u b} / \rho_{b}\right)$, buoyancy and mixture bulk velocity, and (ii) flame burning velocity, which is dependent on the laminar flame speed and the velocity fluctuations. The predictions from the simulations performed using this model showed fair agreement with the experimental data. High-fidelity LES were conducted with the same annular combustor geometry to investigate their ability to accurately capture the main features of the ignition transient [29]. The flame front propagation was in agreement with experimental evidence, demonstrating simulations can provide reliable information on the phenomenon, i.e. flame surface area and heat release rate.

While results from the aforementioned studies are insightful, the experiments covered a narrow range of operating conditions. In particular, they considered one spark location (or just one small region were the spark was located) and the conditions investigated were characterised by a low swirl number [26] and low mixture velocities [27], which increases ignition probability as it would be far from the limiting condition, or both [28]. In addition, it was not possible to distinguish whether the light-round was mainly driven by dilatation or turbulent flame propagation and which mixture characteristic contributes most to light-round time.

However, studies on single burner ignition have shown that the spark location can strongly affect the ignition probability in the combustor [6]. The optimal location for a multiple spark at large radii was found to be at the axial distance where the recirculation zone was the widest [14], where the spark can be stretched by the flow and penetrate into the IRZ, while in a single bluffbody premixed burner the optimum spark location was found inside the IRZ [8], characterised by low velocity and Karlovitz number. Moreover, a recent study on a premixed annular combustor reported that the highest ignition probability requires a spark positioned far downstream in the annular chamber (at five bluff-body diameter distances from a single burner), where the low velocity and turbulent intensity facilitate flame propagation upstream and azimuthally [30].

This work builds upon the studies from Bourgouin et al. [26] and Machover and Mastorakos [27], investigating the ignition transient in a modified geometry of the premixed annular burner from Worth and Dawson $[31,32]$. The combustor was placed horizontally, which allows the potential effect of buoyancy to be as- sessed. A wide range of bulk velocities and equivalence ratios are used, employing methane and ethylene in order to match the laminar flame speed of different mixtures. The flame propagation is observed by imaging $\mathrm{OH}^{*}$ chemiluminescence with two high-speed cameras operated simultaneously, allowing various insights into the ignition processes occurring within the near- and farburner (downstream) regions. In addition, the horizontal orientation allows the exploration of whether buoyancy affects the light-round time; to this end, various azimuthal and axial spark locations are used. The specific objectives of this work are: (i) to investigate the effect of the location of the spark, in the azimuthal and longitudinal direction, on the ignition transient, (ii) to determine the mixture and flow characteristics that drive the light-round process, and (iii) to increase understanding of the mechanisms that drive flame propagation from one burner to another.

\section{Experimental apparatus and methodology}

This section describes the annular combustor employed in the study, the experimental conditions and the techniques used to assess the ignition transient.

\subsection{Premixed annular burner configuration}

Figure 1 shows a schematic of the longitudinal section of the experimental rig (a) and one of a single swirl, bluff body burner (b). The apparatus was adapted and developed from Worth and Dawson [31, 32] and Allison et al. [33]. It was previously employed for an investigation of the lean blow-off behaviour of interacting flames [34] and recently for an investigation on lean ignition and ignition probability [30]. Full details of the setup can be found in these references, thus only a short description is provided here.

In contrast with previous works [27, 31, 33], in this study the burner was placed horizontally. This configuration permits the assessment of buoyancy effects on the ignition mechanism and light-round. The annular combustor was made of an even number of equally spaced, swirled, bluff-body stabilised burners, with the centre of each burner located on a circumference of $170 \mathrm{~mm}$ diameter in an annular enclosure. The inner and outer borders of the geometry were delimited by a $160 \mathrm{~mm}$ long stainless steel cylinder with a diameter of $127 \mathrm{~mm}$ and a $145 \mathrm{~mm}$ long quartz glass cylinder with diameter $203 \mathrm{~mm}$, respectively. The individual burners consisted of a stainless steel tube, $150 \mathrm{~mm}$ long, with an inner diameter of $D_{b}=18.9 \mathrm{~mm}$. Conical bluff bodies $(D=13$ $\mathrm{mm}$ ), with an half angle of $45^{\circ}$, resulting in a blockage 


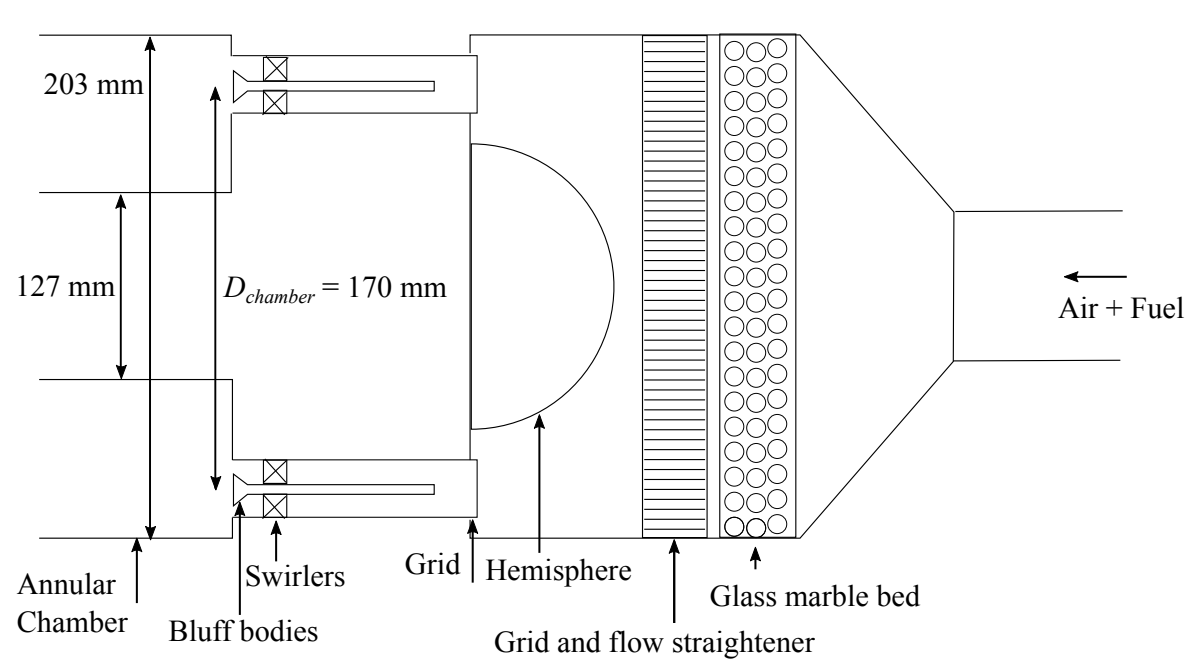

(a)

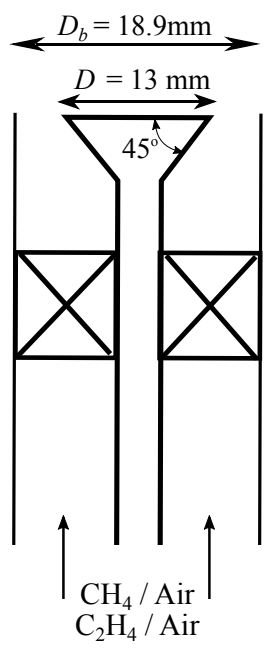

(b)

Figure 1: (a) Schematic of the longitudinal section of the burner and (b) drawing of a swirl bluff body burner.

ratio of $47 \%$ at the exit of the burners, where friction fit in the centre of each pipe. A swirler, composed of a set of six vanes $\alpha=60^{\circ}$ with a geometrical swirl number of 1.22 [32], was placed upstream of each bluff body. This resulted in a anti-clockwise flow direction at the exit of the burners looking top down.

Two different gaseous fuels were employed in the experimental campaign: methane (99.5\% pure) and ethylene $(99.9 \%$ pure). Three Alicat mass flow controllers, with an accuracy of $0.8 \%$ of the set value, were used to deliver the fuel and air to the burner. Fuel and air were fully premixed upstream of the burner and delivered to a common plenum. The plenum consisted of a 200-mm long stainless steel cylinder, with an inner diameter of $212 \mathrm{~mm}$. It contained a bed of 6-mm diameter glass marbles to homogenise the flow, followed by a honeycomb flow straightener to ensure proper flow uniformity prior to reaching the individual burners. From the common plenum, the common mixture was guided into each individual burner by a $140-\mathrm{mm}$ diameter hemispherical body, positioned at the end of the cylinder and attached to the lower of the two plates that held the burners in position. Two sets of plates were manufactured, in order to allocate 12 or 18 individual burners. These resulted in an inter-burner distance of $S_{12}=2.33 D$ and $S_{18}=1.56$ $D$ respectively, facilitating the assessment of flame separation distance on the light-round process.

\subsection{Ignition unit and spark location}

The mixture inside the chamber was ignited using a spark device recently developed in house. The igni- tion unit was composed of a pair of $0.5-\mathrm{mm}$ stainlesssteel electrodes with a spark gap of around $2 \mathrm{~mm}$. The electrodes were connected to a high-voltage transformer (2x5 kV, $20 \mathrm{~mA}$ ) generating sparks over a duration of $\sim 10 \mathrm{~ms}$. The frequency of the sparks was determined by a control system comprising a zero-crossing solidstate relay and a pulse generator, which was limited to a maximum of $100 \mathrm{~Hz}$. A signal generator was set to send one pulse to the relay, resulting in $\sim 2-3$ sparks for each test. The two rods were mounted on a variable position traverse, allowing the longitudinal position of the spark along the annular chamber to be changed. The energy deposited with each spark ( $100 \mathrm{~mJ}$, each spark duration being $10 \mathrm{~ms}$ ) was noticeably higher than the minimum ignition energy for mixtures of methane/air and ethylene/air, for the flow conditions investigated [1].

One aim of this work is to explore the effect of spark location on ignition and light-round. To this extent, the effect of buoyancy in this horizontal configuration was evaluated using four different azimuthal location of the spark. Looking downstream from the top of the annular chamber, the upper region of the annular enclosure was defined as $0^{\circ}$ and the angular direction was prescribed to increase in the anti-clockwise direction, as shown in Fig. 2. The four positions employed were $0^{\circ}, 90^{\circ}, 180^{\circ}$, and $270^{\circ}$. The longitudinal location of the spark was varied to assess the impact igniting further downstream of the bluff bodies had on the light-round mechanism, including upstream flame propagation patterns. In fact, in most gas turbine combustors the igniter is not placed close to the injector but it is distributed among various 


\section{Top view}

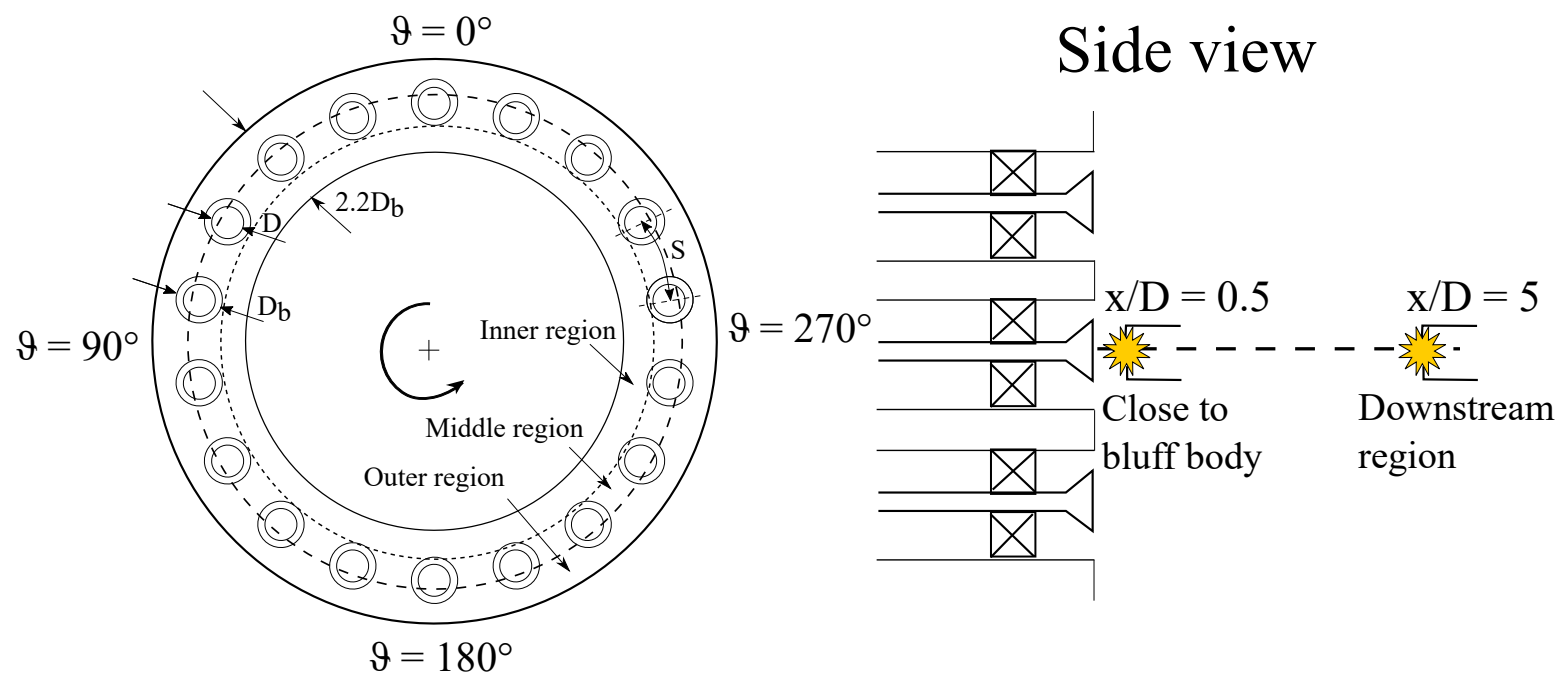

Figure 2: Burner schematic as seen from the top of the chamber and from the side, to show the different spark locations investigated and the regions of the annular chamber.

locations across the liner [1]. Further, sparking downstream inside the chamber has been shown to result in an higher ignition probability [30]. Two different distances were used, defined as $x / D=0.5$ and $x / D=5$, where $D$ $=13 \mathrm{~mm}$ is the bluff body diameter, as can be seen in the side view in Fig. 2. The former lies inside the IRZ of a single burner, while the latter is downstream of the bluff body induced recirculation zone.

\subsection{Experimental conditions}

Tests were performed at a pressure of 1 atm and temperature of $293 \mathrm{~K}$. Each case was repeated at least 3 times, to provide some estimates of the variability of the process. Here, the effect of the azimuthal spark location along with mixture bulk velocity, while keeping fuel and equivalence ratio $(\phi)$ constant, will be discussed first. The flow conditions related to this investigation are reported in Table 1.

The mixture velocities reported in Table 1 were derived by considering the total gas flow rate and the open area of each burner. A range of mixture velocities were investigated which differed depending on the particular burner configuration. Reaching the highest velocity in the 18-burner case used the maximum total flow rate of the facility, and thus the 12-burner configuration, which has a smaller total flow-through area, could attain higher bulk velocities. The different azimuthal locations were tested only for the 18-burner configuration, because, as will be clear from the results, they were found to have little influence on the light-round times.

Then, the campaign focused on evaluating the effect of laminar flame speed and inter-burner spacing on the light-round time. Two different fuels were employed, including cases with different $\phi$ selected so as to match the laminar flame speeds of the mixtures (see Table 2). For all tests, the mixture bulk velocity $\left(U_{m i x}\right)$ was set to $16 \mathrm{~m} / \mathrm{s}$ and the azimuthal spark location (thought not relevant) was $270^{\circ}$.

\subsection{High speed imaging apparatus}

High-speed imaging $(10 \mathrm{kHz})$ of $\mathrm{OH}^{*}$ chemiluminescence, which provides a reasonable estimation of the primary reaction regions [35], was employed to evaluate the mechanism of flame propagation during the ignition transient and the light-round. The imaging system consisted of two cameras, one located in front of the burner, capturing an axial view of each burner in order to see the flame front motion, the other was positioned on the side of the annular combustor, used for a close view of a subset of burners. Hereinafter, the former and the latter will be referred to as the "Top view" and "Side view", respectively. Each camera is a Photron SA1.1 high-speed CMOS camera, with a maximum resolution of $1024 \times 1024$ pixels at a framing rate of 5.4 $\mathrm{KHz}$. In this study, images were collected at a rate of $10 \mathrm{kHz}$, which required operating the cameras with a reduced sensor area of $768 \times 640$ pixels. The projected 
Table 1: Flow conditions for the cases assessing the effect of the azimuthal spark location and mixture velocity.

\begin{tabular}{cccccc}
\hline \# Burners & Fuel & $\phi$ & Spark lon. loc. $(x / D)$ & Spark az. loc. $\left({ }^{\circ}\right)$ & $U_{m i x}(\mathrm{~m} / \mathrm{s})$ \\
\hline 18 & $\mathrm{CH}_{4}$ & 0.75 & $0.5-5$ & $0-90-180-270$ & $10-16-20$ \\
12 & $\mathrm{CH}_{4}$ & 0.75 & $0.5-5$ & 270 & $10-16-20-25-30$ \\
\hline
\end{tabular}

Table 2: Flow conditions for the tests on the effects of mixture properties. For all cases the spark azimuthal location was fixed at $270^{\circ}$ and $U_{m i x}=$ $16 \mathrm{~m} / \mathrm{s}$. Unstable refers to the possibility of rise of thermoacoustic instabilities following ignition.

\begin{tabular}{cccccc}
\hline \# Burners & Fuel & $\phi$ & Spark loc. $(x / D)$ & $S_{L}(\mathrm{~cm} / \mathrm{s})$ & Unstable \\
\hline 18 & $\mathrm{CH}_{4}$ & $0.75-0.85-1$ & $0.5-5$ & $24-30-36$ & No \\
18 & $\mathrm{C}_{2} \mathrm{H}_{4}$ & $0.58-0.62-0.67$ & $0.5-5$ & $24-30-36$ & No \\
12 & $\mathrm{CH}_{4}$ & $0.75-0.85-1$ & $0.5-5$ & $24-30-36$ & No \\
12 & $\mathrm{C}_{2} \mathrm{H}_{4}$ & $0.58-0.62-0.67$ & $0.5-5$ & $24-30-36$ & No \\
18 & $\mathrm{C}_{2} \mathrm{H}_{4}$ & 0.77 to 0.9 & $0.5-5$ & 47.5 to 59.5 & Yes \\
12 & $\mathrm{C}_{2} \mathrm{H}_{4}$ & 0.74 to 0.9 & $0.5-5$ & 47.5 to 59.5 & Yes \\
\hline
\end{tabular}

pixel size was $0.38 \mathrm{~mm} /$ pixel for the Top view and 0.32 $\mathrm{mm} /$ pixel for the Side view. Coupled to each camera was a high-speed intensifier (LaVision IRO), which was gated to $93 \mu$ s for a $10 \mathrm{kHz}$ frame rate. The gain of the IRO was adjusted for each case to avoid saturation while providing the best signal-to-background ratio as possible. A UV $100 \mathrm{~mm} \mathrm{f} / 2.8$ lens (Cerco 2178) fitted with a narrow bandpass filter $(310 \mathrm{~nm}+/-5 \mathrm{~nm})$ was attached to the IRO, used at $\mathrm{f} / 2.8$. In order to obtain simultaneous top and side view videos of the propagating flame front the two cameras were synchronised using an external waveform generator. Additionally, a signal generator was used to trigger the spark generator and the video recording. For each test between 700 and 1000 images were saved, depending on the duration of the light-round. The first frame saved was chosen as the first image in the sequence where the spark was clearly visible.

\subsection{Ignition procedure and evaluation of the light- round time}

Each test was conducted following the same routine. First, with the air flowing, the fuel mass flow controller was opened for 2 seconds and after the signal generator triggered the spark device and the camera recording. This allowed the annular chamber to be filled with a flammable mixture before ignition. Under these initial conditions, flame propagation could occur in all directions: upstream, downstream, and azimuthally inside the chamber. From the initial flame kernel, two flame branches were formed, which propagated around the annular chamber in the clockwise and anti-clockwise directions. The end of the ignition process was defined as the moment when these two flame branches merged inside the chamber, which typically happened opposite to the spark. After the ignition event, the fuel supply was shut down to extinguish the flame, but the air was not stopped so that the burner could cool. Each test was conducted after at least $60 \mathrm{~s}$, ensuring the temperature of the chamber walls had returned to ambient conditions (293 K).

The light-round time was estimated by employing the following procedure to analyse the images collected from the top view. Namely, the $\mathrm{OH}^{*}$ signal was averaged over the full extent of each frame to produce a 1-D signal as a function of time (see Fig. 3).

The formation, growth, and stabilisation of a flame kernel (phases 1-3) occur over a duration of 3 to $10 \mathrm{~ms}$ after the deposition of the spark. The beginning of the light-round is related to the propagation of the incipient flame to the adjacent burner, which can be identified by the sharp increase in the 1-D signal in Fig. 3. In particular, the time associated with the beginning of the light-round process was defined as the moment when the signal reaches $3 \%$ of the maximum value and the merging of the two flame branches occurred when the signal reached its maximum. At the time instant corresponding to this threshold, a flame kernel larger than one single burner could be easily detected and distin- 


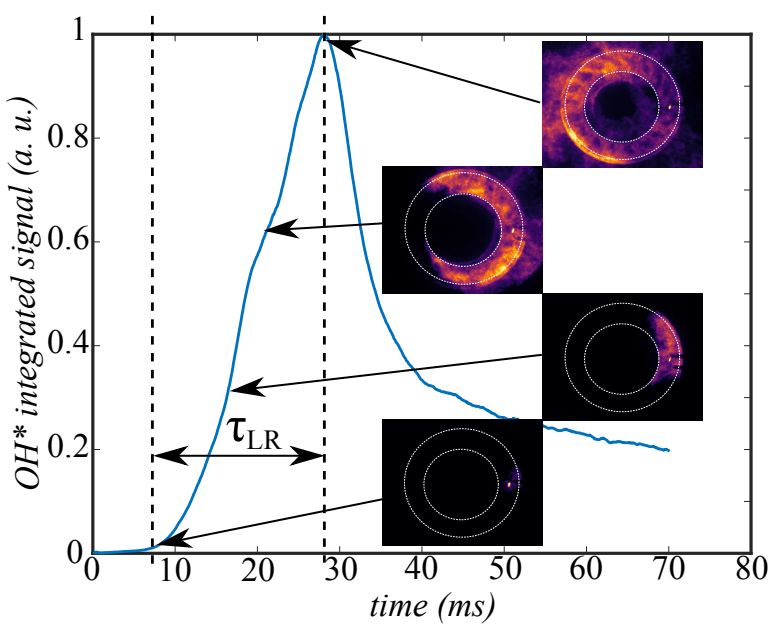

Figure 3: 1-D signal of the integrated $\mathrm{OH}^{*}$ chemiluminescence over time from the top view images. The pictures reported show the evolution of the light-round at different values of the signal.

guished from the spark. The light-round time $\left(\tau_{L R}\right)$ was obtained as the difference between the merging time and the time of the beginning of the light-round process. A manual analysis of the top and side image sequences confirmed this methodology provided a reasonable estimate of the merging time.

\section{Results and discussion}

\subsection{Visualisation of the light-round process}

First, an overall description of the light-round process will be provided. Following that is an assessment of the initial flame propagation process. Finally, the burnerto-burner propagation of the flame front is analysed and discussed.

\subsubsection{Overview}

As the annular chamber is filled with a flammable mixture before sparking, the hot products ignite fresh reactants downstream of the spark. This resulted in $\mathrm{OH}^{*}$ laden products filling the chamber and being convected towards the top camera. Thus, by using an additional side-view camera, both the axial and azimuthal flame propagation can be monitored in a selected region, which facilitates a more detailed assessment of the overall light-round process.

Figure 4 shows ignition sequences of the annular combustor with the sparks placed at four different azimuthal locations while the longitudinal location was held fixed at $\mathrm{x} / \mathrm{D}=5$. The $\mathrm{OH}^{*}$ signal that can be seen outside the annular chamber is due to the downstream convection of the hot gases that eventually exit the outer walls of the enclosure. Videos showing the ignition transient for different conditions are provided as Supplementary Material. The simultaneous side view showed a different perspective of the light-round, depending on the azimuthal position of the spark. First, the spark ignited the fresh reactants in the surrounding area, generating a flame kernel, as shown in Fig. 4a at $t=10$ $\mathrm{ms}$. At $t=15 \mathrm{~ms}$ the flame kernel growth is apparent (see Fig. 4a). From here the kernel was convected downstream by the bulk flow, yet at the same time propagating upstream towards the bluff bodies. This is associated with a flame propagation in the longitudinal and azimuthal directions. The pattern is clearly evident in the side view sequences in Figs. $4 \mathrm{~b}$ and $4 \mathrm{c}$ at $t=23 \mathrm{~ms}$, when the spark locations were $0^{\circ}$ and $180^{\circ}$. As the $\mathrm{OH}^{*}$ chemiluminescence is a line of sight technique, images show the signal integrated over the depth of the field of view. Thus, notice that considering the top view alone leads to the erroneous conclusion that half of the burners were ignited. Yet, as is evident from the side view (see Figs. 4b and 4c) the flame front was propagating azimuthally at a set distance above the burners (i.e. the flames were not anchored to the bluff bodies). The lightround mechanism was comprised of two main parts: (i) downstream azimuthal expansion of the flame front and (ii) upstream propagation of the flame kernel and ignition of the burners, followed by burner-to-burner propagation close to the bluff bodies.

These two phenomena develop simultaneously within the chamber, implying a complex propagation mechanism. This mechanism is distinctly different from that reported in Refs. [26, 27] where the ignition process was characterised by a "sawtooh" pattern, albeit in experiments with a spark located near the burners. As depicted in Figs. $4 \mathrm{~b}$ and $4 \mathrm{c}(t=23 \mathrm{~ms})$ and Fig. $4 \mathrm{~d}(t=30 \mathrm{~ms})$, when a flame fragment from the main front entered the inner recirculation zone (IRZ) of a single burner it led to flame anchoring and stabilisation on the bluff body. Anchoring and stabilisation of the flame over each individual burner was due to both patterns of propagation.

Figure 5 shows the corresponding image sequence for the same gaseous mixture but with the spark located close to the bluff body $(x / D=0.5)$. In this case, the light-round process was similar to what observed in Refs. [26, 27]. The initial kernel developed inside the IRZ of a single burner and expanded (see Fig. 5a, $t=7$ $\mathrm{ms}$ ), igniting the fresh mixture in the inter-burner region as well as just downstream of the spark location. Following this, as shown in the side view Figs. $5 \mathrm{~b}$ and $5 \mathrm{c}$ between $t=12 \mathrm{~ms}$ and $t=17 \mathrm{~ms}$, the flame front propagated over the bluff bodies, igniting each individual 


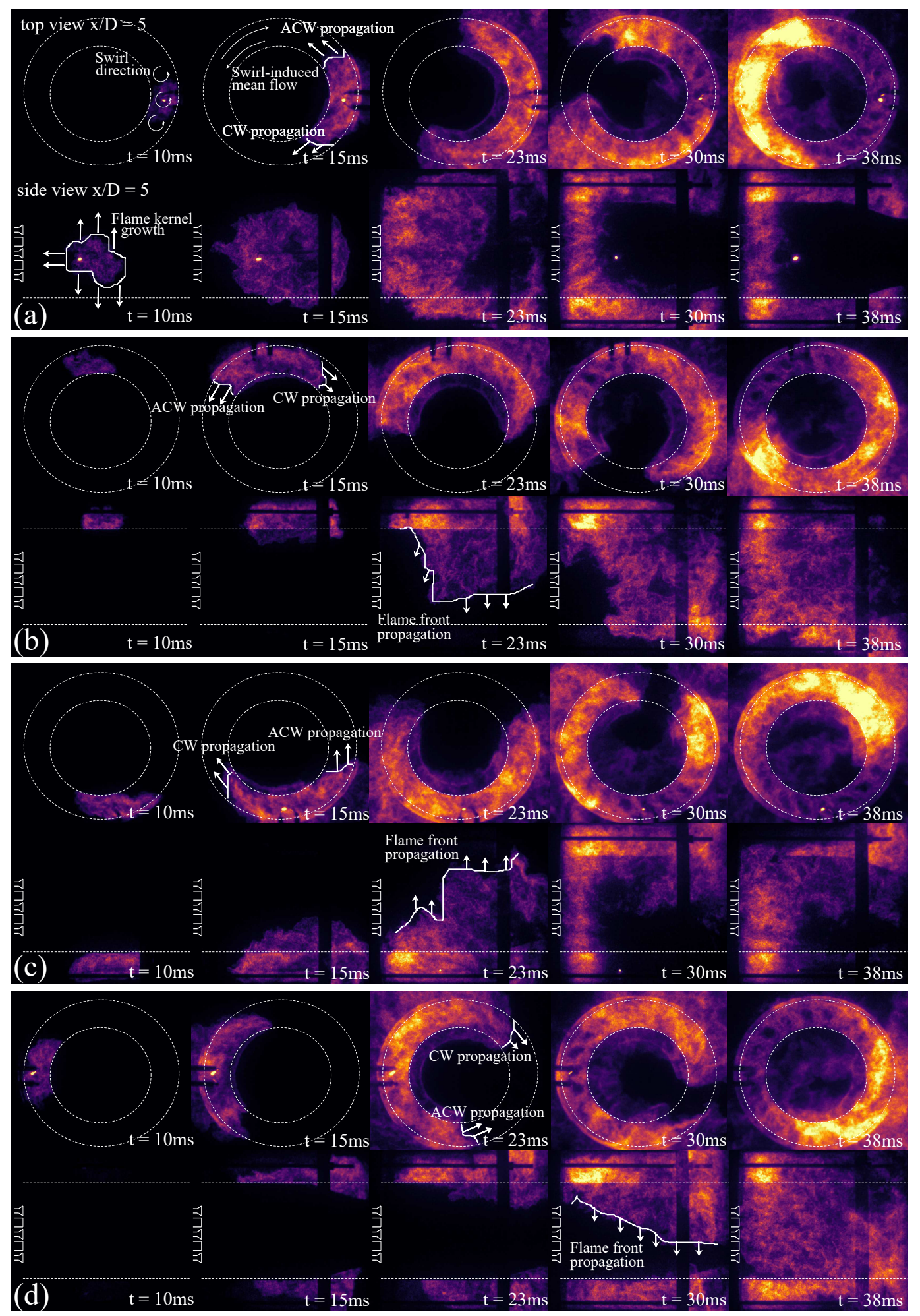

Figure 4: Light-round ignition sequences of the annular combustor when the spark was located at the four azimuthal locations (in order from the top: $270^{\circ}, 0^{\circ}, 180^{\circ}, 90^{\circ}$ ) in the 18-burner system, for a spark located at $x / D=5$ and a mixture of methane/air with $\phi=0.75$ and $U_{m i x}=16 \mathrm{~m} / \mathrm{s}$. 

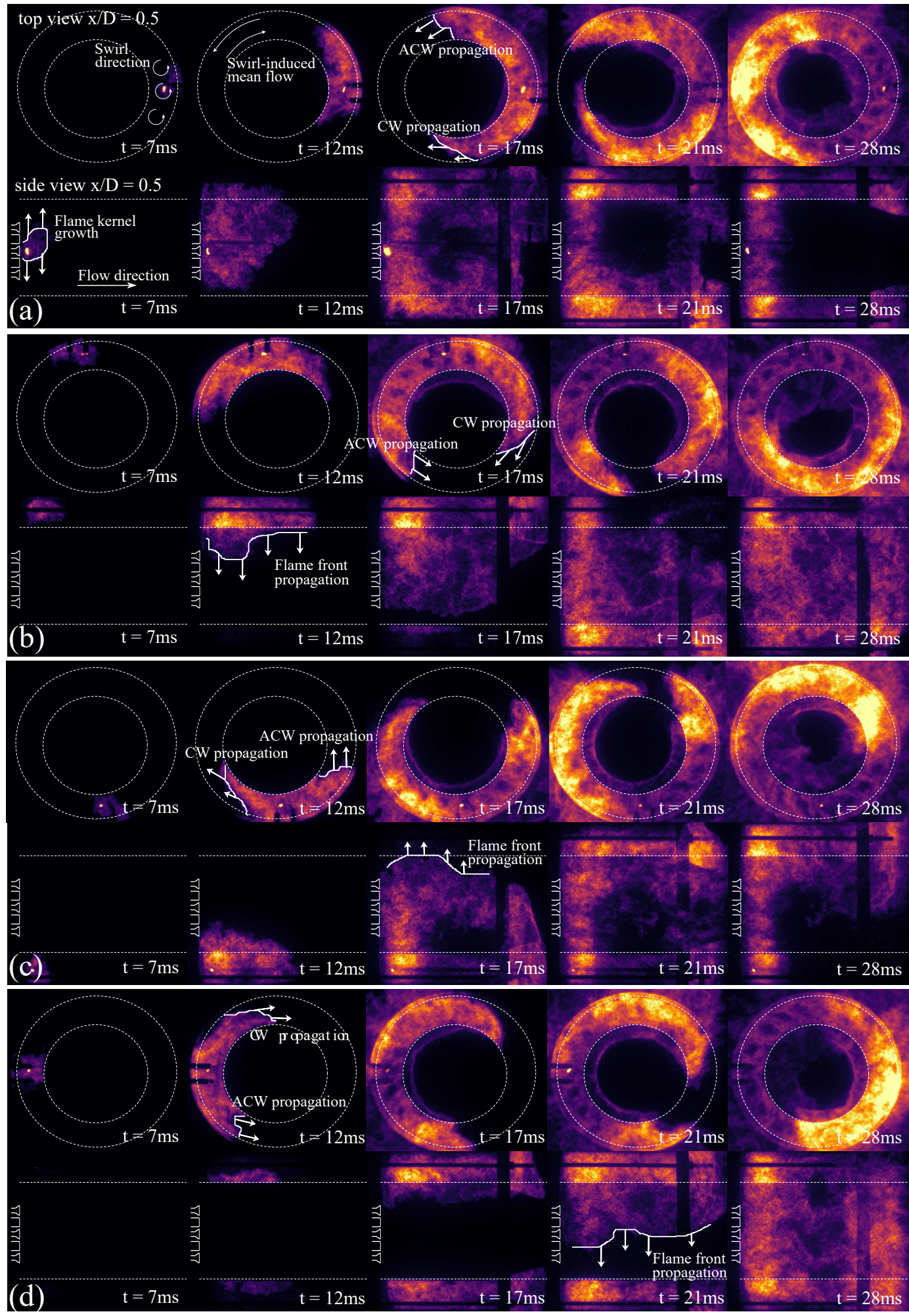

Figure 5: Light-round ignition sequences of the annular combustor when the spark was located at the four azimuthal locations (in order from the top: $270^{\circ}, 0^{\circ}, 180^{\circ}, 90^{\circ}$ ) in the 18 -burner system, for a spark located at $x / D=0.5$ and a mixture of methane/air with $\phi=0.75$ and $U_{m i x}=16 \mathrm{~m} / \mathrm{s}$. 


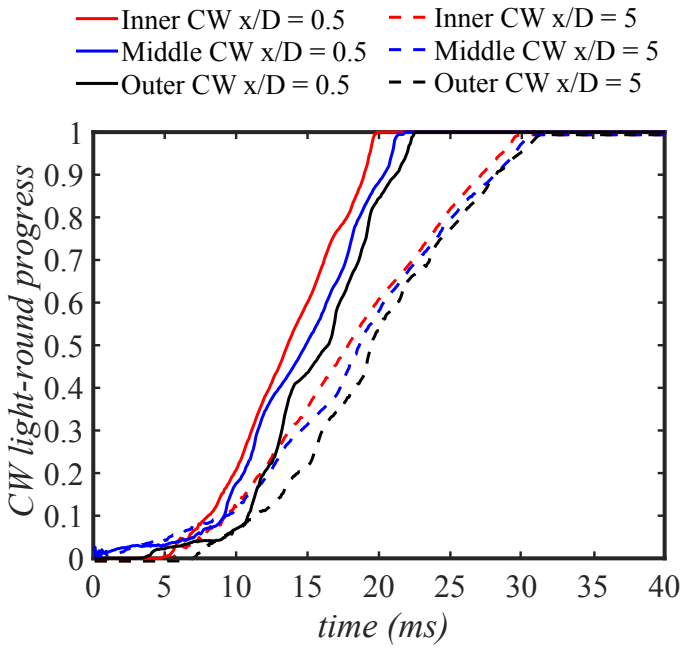

(a)
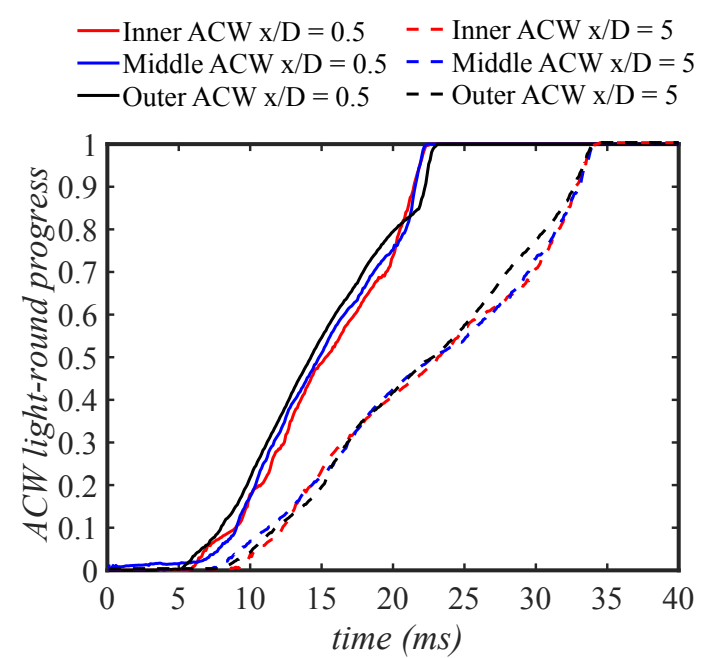

(b)

Figure 6: Signals representing the progress of the light-round process in 3 different regions of the annular chamber: close to the inner border of the chamber (inner), in the middle of chamber (middle) and close to the outer border (outer), as reported in Fig. 2 . The signals are divided in CW (a) and ACW (b) propagation depending on which of the two propagating flame branches is considered. The operating conditions are: 18-burner, mixture of methane/air $\phi=0.75$ and $U_{\text {mix }}=16 \mathrm{~ms}$ and two different longitudinal spark locations are reported, $x / D=0.5$ and $x / D=5$.

burner. The propagation appeared to be fairly uniform, with a flame edge that can be clearly detected in the side view images provided in Figs. $5 \mathrm{~b}$ and $5 \mathrm{c}(t=12 \mathrm{~ms})$ and in Fig. $5 \mathrm{~d}(t=12 \mathrm{~ms}$ and $t=17 \mathrm{~ms})$. Burner-to-burner propagation, in particular for low bulk velocities (10$16 \mathrm{~m} / \mathrm{s}$ ), exhibited a pattern similar to that in Ref. [27]. When the flame front passed over a burner, flame pockets were captured by its IRZ (see the frames from $t=$ $12 \mathrm{~ms}$ to $t=21 \mathrm{~ms}$ in Figs. $5 \mathrm{~b}, 5 \mathrm{c}$ and $5 \mathrm{~d}$ ) leading to the subsequent stabilisation of the flame over the burner. From this time series, it is evident that the light-round is faster when sparking close to the bluff body, which will be discussed at length in Section 3.2. Namely, in the image sequences in Figs. 5a to d the two flame branches merged after $\sim 28 \mathrm{~ms}$, while it took at least $10 \mathrm{~ms}$ more for the corresponding cases shown in Figs. 4 a to $4 d$.

In each sequence of images in Figs. 4 and 5 the influence of the flow field and swirl direction on the lightround process is clearly visible. The two flame branches tended to follow the path induced by the relatively large tangential flow component induced by the strong swirl near the bluff bodies, thus favouring clock-wise (CW) propagation on the inner side of the annular chamber and anti clock-wise (ACW) propagation on the outer side of the annular chamber. Similar observations are reported in Refs. [26, 27]. In an attempt to quantify the asymmetry of the flame front, the integrated $\mathrm{OH}^{*}$ signal was computed along three regions of interest forming rings evenly spaced in the annular chamber. These were placed near the inner side, the middle, and the outer side of the annular chamber (see the schematic in Fig. 2 for the regions involved). Figure 6 displays plots of the progress of the light-round in the $\mathrm{CW}$ (6a) and ACW (6b) direction over time from two cases with longitudinal spark locations of $x / D=0.5$ and 5, respectively. To obtain these plots, images from the top view were binarised and the progress of the light-round process was calculated as the ratio between the ignited pixels (signal equal to 1 ) to the total number of pixels in a specific region. In the $\mathrm{CW}$ direction (see Fig. 6a), the light-round near the inner part of the chamber progressed more quickly that the outer part. In contrast, in the ACW direction (see Fig. 6b) the flame front travelled faster in the outer part of the chamber compared to the inner part. This is due to the influence of the swirl on the direction of the propagation pattern.

The consideration of different longitudinal locations further highlights different propagation patterns. Specifically, as is shown in Figs. $6 \mathrm{a}$ and $6 \mathrm{~b}$ the time lag between the signals is higher in the case with $x / D=0.5$ than with $x / D=5$, regardless of propagation direction. This can also be seen in the top view images in Fig. 5, where the flame front appeared asymmetric (leaning towards the inner side of the chamber in $\mathrm{CW}$ direction and the outer side in the ACW), while in Fig. 4 the asymmetry is only highlighted by the different propagation speed of the two sides of the flame. The CW branch, traversing the annular enclosure on the inner side, fol- 
lowed a shorter path, thus being able to make further progress than the ACW branch in the same time. As a result, in the graphs in Fig. 6, the time lag between the signals is narrower in the ACW direction compared to the $\mathrm{CW}$. Therefore, regardless of the spark location, the merging position is always shifted towards the ACW side of the flame front. Moreover, the spark azimuthal location had little influence on the flame kinematics and on the light-round time, indicating that buoyancy weakly affects this process.

\subsubsection{Initial propagation}

The light-round mechanism exhibited a strong dependence on the longitudinal spark location as this influenced the initial propagation of the flame kernel (second and third phases of the ignition process [6]). This can be analysed from the initial frames in the first image sequences in Figs. 4 and 5, when the spark was located at the azimuthal location $270^{\circ}$ such that the side camera could capture the part of the annular chamber where the spark was located.

After the formation of the initial flame kernel, when the spark was located at $x / D=5$ (see Fig. 4a), the development of the flame followed the swirl-induced flow pattern and proceeded quasi-spherically, as shown at $t=10$ $\mathrm{ms}$ and $t=15 \mathrm{~ms}$. The flame front propagated upstream while simultaneously igniting the unburnt mixture further downstream and in the azimuthal direction (see the white arrows in the side view at $t=10 \mathrm{~ms}$ ). The first burner ignited shortly after $t=15 \mathrm{~ms}$, while from the top view almost half of the annular chamber appeared lit. In this instance, the first burner to ignite was the one directly upstream of the spark location; however, at times initial flame anchoring involved two to three burners simultaneously. Then, the flame front began to propagate from burner to burner (see $t=23 \mathrm{~ms}$ ) close to the bluff bodies. This resulted, as previously stated, in a mixed mode of the light-round mechanism, which is clearly observed to be dependent on the initial stage of propagation.

Fig. 7 reports the time it took for the flame front to travel upstream and ignite the first burners when the spark was located at $x / D=5$, against the bulk velocity of the mixture. Flame propagation towards the first burner evolved over a time scale comparable to the total light-round itself. That is, if the time from the spark to the anchoring of the flame on the first burner was subtracted from the total light-round time (reported in the next section), one does not recover the measured lightround time for the case with a spark located at $x / D=$ 0.5. This implies that the light-round process does not

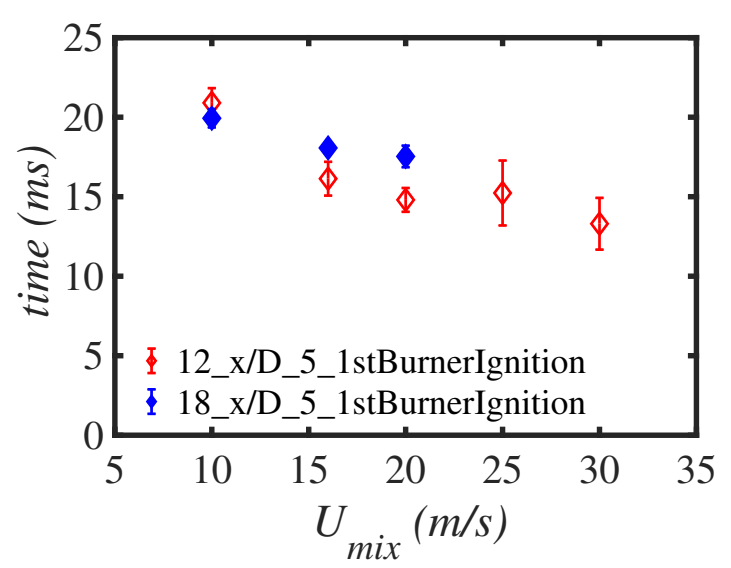

Figure 7: Time delay between the spark and the ignition of the 1st burner (defined as the moment when the flame front reaches the bluff body) as a function of $U_{\text {mix }}$, in the 12- and 18-burner configurations with spark located at a longitudinal position $x / D=5$. The error bars represent the standard deviation for each case, out of three tests performed.

start just after the flame reaches the first burner but earlier, together with the upstream propagation. This is further evidence that the light-round transient is driven by simultaneous upstream and azimuthal flame propagation that drives the light-round from an initial spark located downstream in the combustion chamber. Additionally, as $U_{m i x}$ increased, the flame reached the individual burners earlier from the initial downstream location, for both configurations. This is likely a result of two effects: (i) enhanced flame propagation due to increased turbulence intensity, and (ii) enhanced convection of the flame driven by increased tangential velocity and recirculation near the bluff bodies. Higher $U_{\text {mix }}$ results in increased velocity fluctuations and their RMS value $\left(u^{\prime}\right)$ and thus affects the turbulent flame speed [36-38]. Further, when increasing the bulk velocity, the magnitude of the recirculation velocity also increases, as well as the swirl induced tangential velocity. This likely affects the initial flame propagation, favouring the upstream propagation and anchoring of the flame. Therefore, the combined effect of enhanced flame-front propagation (as a result of increased turbulence intensity) and convection (due to increased recirculation and tangential velocity) reduces the time it takes the initial flame kernel to reach the first burner. These data help corroborating the evidence that light-round is faster for higher mixture bulk velocities, that will be shown in the next section of this work and has been reported in previous papers [23, 24, 26, 27].

The initial propagation in the case of a spark located close to the bluff body at $x / D=0.5$ followed a differ- 
ent pattern (see the first image sequence, with the spark located at $270^{\circ}$, in Fig. 5a). After the formation and growth of a flame kernel inside the IRZ of one burner $(t$ $=7 \mathrm{~ms}$ ), the flame started to spread to the adjacent burners $(t=12 \mathrm{~ms})$ creating two flame branches with a compact flame front. This resulted in a $\mathrm{CW}$ and ACW propagation of the flame, following the direction of the swirl. In this case, light-round is fully equivalent to ignition of individual burners in their IRZ, as sparking close to the bluff body resulted in burner-to-burner propagation as the main pattern for the light-round. Inspecting Fig. 5 indicates that analysing images collected from the top view is sufficient to describe the progress of the lightround in this case.

\subsubsection{Burner-to-burner propagation}

The core of the light-round process is the burner-toburner propagation of the flame front, resulting in the ignition and stabilisation of the flame over the individual burners. It was possible to evaluate the mechanism of the light-round through the side view images taken from the cases with the spark at azimuthal locations of $0^{\circ}$ and $180^{\circ}$. In particular, the former was useful to understand the flame-front kinematics in its $\mathrm{CW}$ branch, where propagation occurs in the inner side of the annular chamber. On the other hand, with the spark at $180^{\circ}$, the ACW branch of the flame front was clearly observed propagating along the outer side of the enclosure.

Figure 8a permits a more detailed inspection of the flame front propagation when the initial longitudinal spark position was at $x / D=5$. From the top sequence of images it can be clearly observed that the flame front was propagating both towards the bluff bodies from the downstream and in the azimuthal direction. Between $t=26 \mathrm{~ms}$ and $t=28 \mathrm{~ms}$ these two modes of propagation appeared to alter the shape of the flame front, which bends over the burners causing them to ignite. Gas expansion driven by the flow and turbulent flame propagation are considered to be the first order driving forces of the light-round [26, 27]. In this case, the position of the initial kernel, from which the whole combustor was ignited, generated a complex propagation pattern comprised of two separate modes (upstream propagation and burner-to-burner propagation). Similar features are present when looking at the second sequence of images in Fig. 8a, which shows the propagation of the ACW branch of the flame front. The ignition of the burner was more closely linked to the propagation of the flame close to the bluff bodies and the flame front was clearly skewed in the longitudinal direction. However, the general pattern was the same.
Figure $8 \mathrm{~b}$ presents a sequence of instantaneous images for the same flow condition as in Fig. 8a, only with the spark located close to the bluff body $(x / D=0.5)$. It is possible to identify a fairly compact and uniform flame front sweeping over the burners. Yet, clear differences can be seen when looking at the propagation in the CW (top series of images) and ACW (bottom series of images) directions. When the flame front travelled in the $\mathrm{CW}$ direction it tended to be skewed towards the inner side of the annular enclosure. This resulted in a fast propagating flame edge, that may overcome the burners before completely stabilising on them. This is evident from the images between $t=17 \mathrm{~ms}$ and $t=21 \mathrm{~ms}$. Ignition of the three burners in the centre of the image occurred at approximately the same time (i.e., the flame front propagated upstream igniting the individual burners simultaneously). This could affect the sequentiality of the light-round process. Thus, even when sparking close to the burners, the $\mathrm{CW}$ branch of the flame front was characterised by a complex pattern of burnerto-burner propagation, ignition, and stabilisation of the individual flames. In contrast, the ACW branch (see the bottom series of images in Fig. 8b) showed a simple sequence of propagation, similar to the one reported by Machover and Mastorakos [27]. A detailed quantification of the burner-to-burner is provided in the Supplementary material. The key finding was that burner-toburner propagation was observed to be characterised by higher variability and a general increase in the time delay between the flame propagation from a burner to the adjacent one by $\sim 1-2 \mathrm{~ms}$ in cases with the spark located downstream, compared to cases with the spark located close to bluff bodies.

\subsection{Light-round time and speed of propagation}

The end of the ignition transient in the annular chamber was defined as the moment when the two flame branches merged. As discussed in Section 2.5, the lightround time $\left(\tau_{L R}\right)$ was evaluated by analysing the top view image sequences obtaining $1 \mathrm{D}$-signals over time. In the horizontal configuration, as in realistic gas turbine combustors, buoyancy has the potential to affect the ignition process. To investigate this aspect, four different azimuthal locations of the spark were employed while operating with the 18-burner configuration. In addition, at each azimuthal location, the spark was placed at two separate longitudinal locations: close to the bluff bodies $(x / D=0.5)$ and downstream in the annular chamber $(x / D=5)$. As previously described, the propagation pattern varied with longitudinal spark location. 

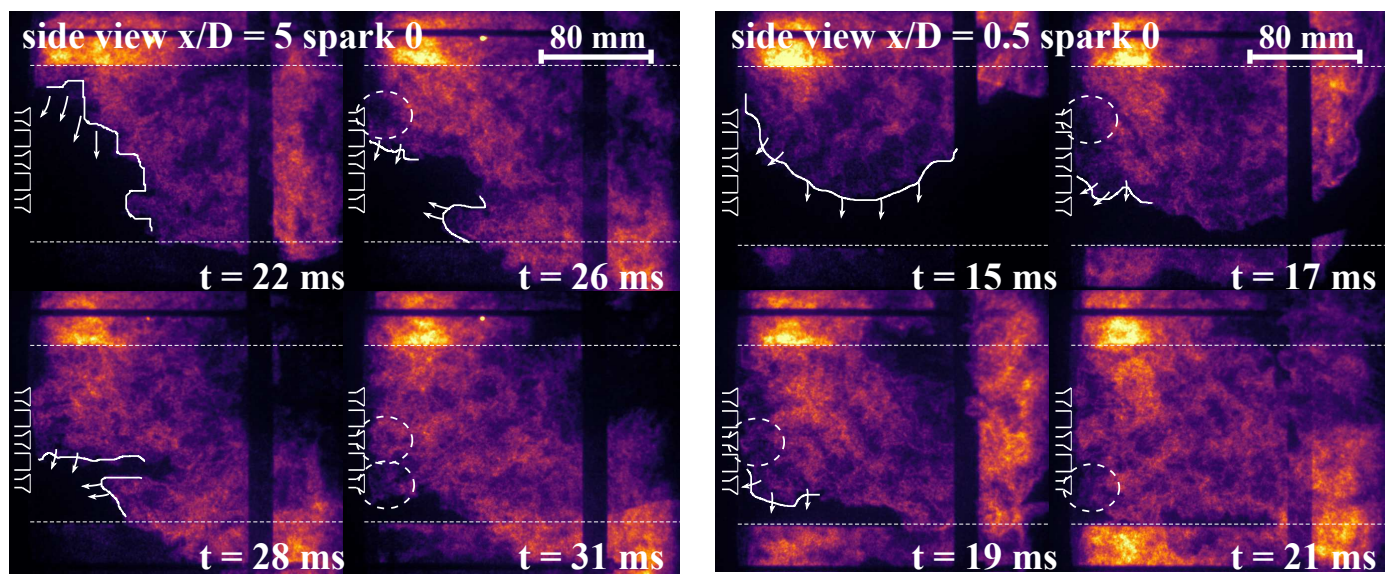

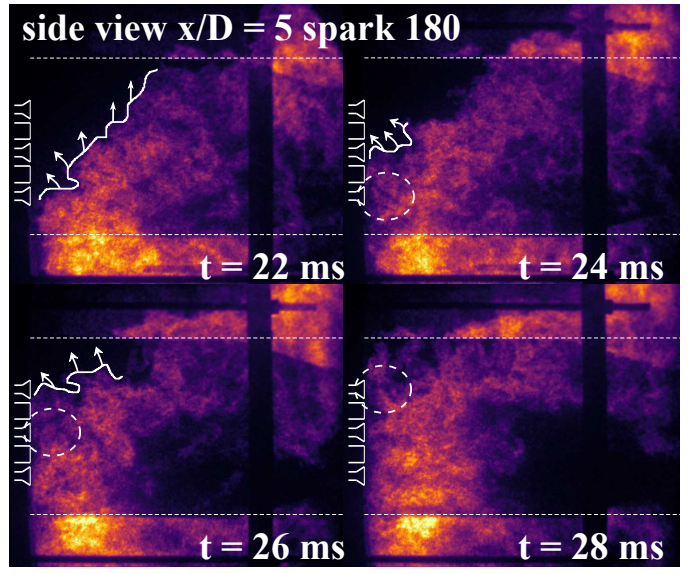

(a) Spark located at $\mathrm{x} / \mathrm{D}=5$

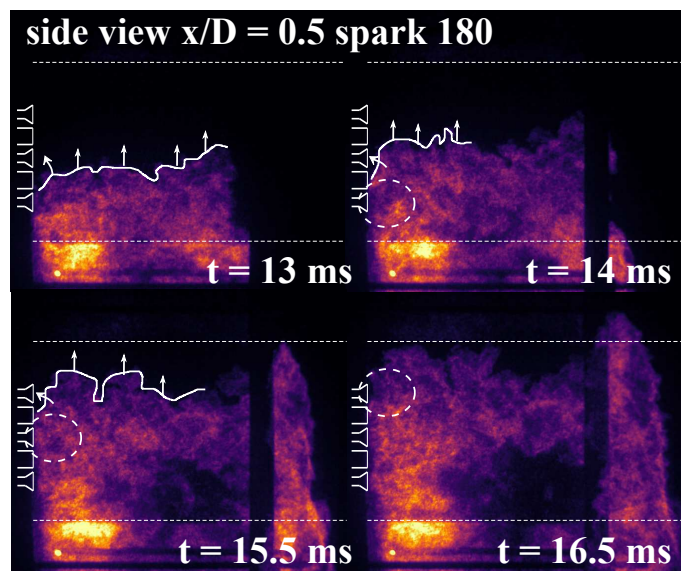

(b) Spark located at $\mathrm{x} / \mathrm{D}=0.5$

Figure 8: Side view images of the burner-to-burner propagation. The sequences from spark 0 report the propagation of the flame front in the $\mathrm{CW}$ direction, while the sequences from spark 180 report the ACW flame propagation. Flow conditions: $\phi=0.75$ and $U_{m i x}=20 \mathrm{~m} / \mathrm{s}$.

Figure 9a presents measured light-round times from the 18-burner configuration. Specifically, these data were obtained with a fixed methane/air mixture $(\phi=$ 0.75 ) and varying the bulk velocity of the gases, for all the aforementioned spark locations. The light-round time was weakly affected by the azimuthal location of the spark. The initial kernel developed into flame branches that always followed the rotational flowfield near each burner, propagating ACW on the outer enclosure and CW near the inner enclosure. Due to the high swirl number, the flame front pathway was strongly influenced by the local flow conditions. This suggests that buoyancy-driven effects related to the position of the ignition source have negligible impact on the light-round. The swirl-induced rotational flow inside the chamber is likely the main driver of the direction of the light-round process.

The strong influence of the swirl direction on the propagation pattern could be expected when sparking close to the bluff bodies. That is, the relatively high swirl-generated tangential velocity at the exit of each burner, coupled with the IRZ behind the bluff body, imposes a strong recirculating pattern, forcing the propagation in the flow direction. However, the same trend was shown in tests with the spark placed at a longitudinal location of $x / D=5$, regardless of the greater variation in the light-round time due to the complex propagation pattern. Thus, it is possible that downstream of the bluff bodies the expanding gases are still influenced by the bulk swirl in the chamber (also shown in the image sequences in Fig. 4). Moreover, as previously described, in these tests the light-round mechanism followed two patterns of propagation: azimuthal and upstream, where the latter was followed by burner-to-burner propagation. Specifically, burner-to-burner propagation was found to play the major role in flame anchoring and stabilisation 


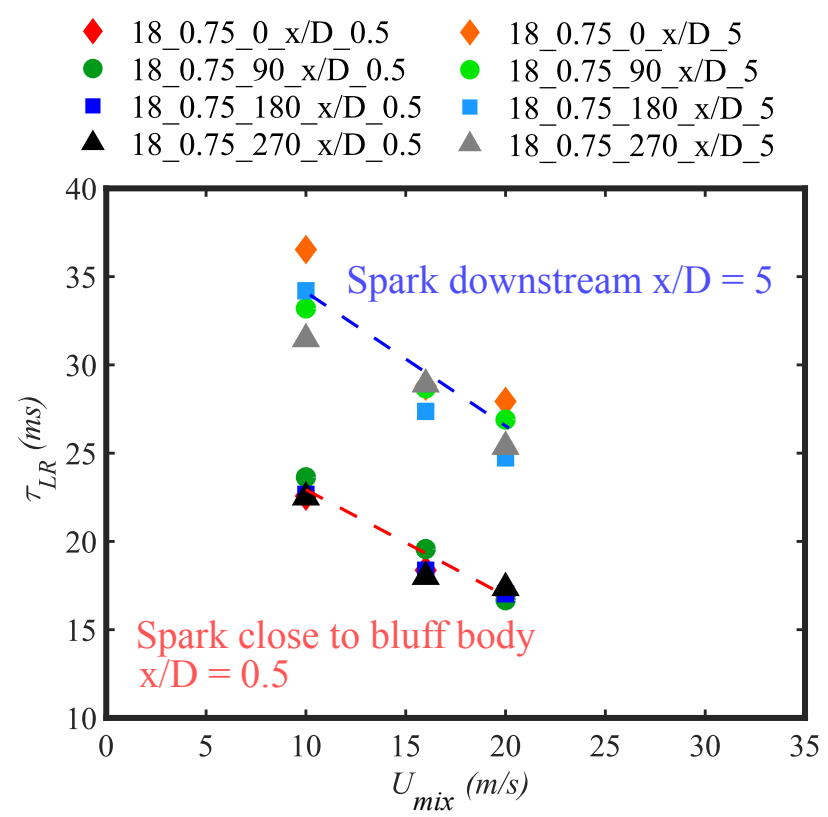

(a) $\triangleright$ 12_0.75_x/D_0.5 $\triangle 18 \_0.75 \_\mathrm{x} / \mathrm{D} \_0.5$

$\triangleright 12 \_0.75\left[\mathrm{x} / \mathrm{D} \_5 \times 18 \_0.75 \_\mathrm{x} / \mathrm{D} \_5\right.$

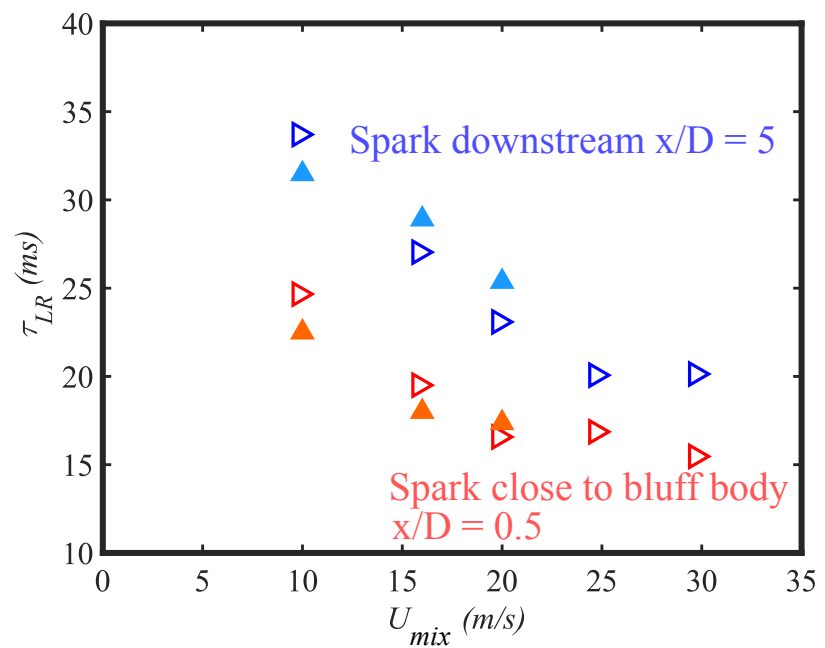

(b)

Figure 9: Total light-round time for three different bulk velocities, four azimuthal spark locations and two longitudinal spark locations in the 18burner configuration (a) and comparison between 12-burner (hollow markers) and 18-burner (filled markers) configurations (b). The reactants were comprised of methane and air with $\phi=0.75$. Each point is the average of at least three tests. Label is in the form of XX_ $\phi_{-} A_{-} \mathrm{X} / \mathrm{D}_{\perp} \mathrm{L}_{\text {, where }} \mathrm{XX}$ is the number of burners, $\phi$ is the equivalence ratio and $\mathrm{A}$ and $\mathrm{L}$ are the azimuthal and longitudinal spark locations, respectively. The dashed lines are reported to highlight the main trends in the graph.

on the bluff bodies. In addition, it was significantly influenced by the local flow field near the bluff bodies. This can explain why, regardless of the longitudinal location of the initial spark, it appeared that buoyancy has negligible effect on the light-round process.

Figure 9a considers all azimuthal and longitudinal spark locations, at a fixed $\phi$ and inter-burner spacing and highlights the relationship between light-round time and mixture velocity. In agreement with prior experimental works on annular configurations [23, 24, 26, 27], lightround times are found to decrease with increasing bulk velocity of the gaseous mixture. This may be related to: (i) the increase of turbulent intensity that results in an increase of the turbulent flame speed $\left(S_{T}\right)$ [36-38], and (ii) enhanced convection of the flame due to increased recirculation and tangential velocity.

The combined effects of inter-burner spacing and mixture velocity is reported in Fig. 9b. Taking into account the uncertainties in the measurements of the $\tau_{L R}$, the two configurations were found to behave similarly. For different $U_{m i x}$ values, the flame front was not observed to travel preferentially faster in any of the two configurations. Thus, due to the complexity of the propagation phenomenon, no relevant correlation can be drawn between inter-burner spacing and light-round time for these experimental conditions. This result is in contrast with that reported by Machover and Mastorakos [27]. Such discrepancy likely stems from the added information provided by the side-view camera employed here. Namely, the presence of a simultaneous side-view helped correcting and improving the information obtained from the solely top view. Furthermore, the range of cases investigated here is broader, which helps identify the presence, or lack thereof, a correlation within the data.

Due to the smaller overall flow-through area, higher mixture velocities were obtained with the 12-burner configuration. From Fig. 9b it appears that the lightround time begins to plateau for $U_{m i x}>20 \mathrm{~m} / \mathrm{s}$. Experiments with higher mixture velocities are needed to fully verify this trend. This possible plateauing of the light-round time is likely a consequence of competing effects. Both the tangential and recirculation velocities increase with $U_{m i x}$, as does $u^{\prime}$ and subsequently, $S_{T}$, all of which enhance flame propagation from one burner to the next. Of course, there is a limit to this enhancement, which is likely associated with the "bending" behaviour of $S_{T}$ with increase $u^{\prime}[36,38-40]$ as well as with an increased propensity of strain-induced extinction [8, 4144]. Thus, plateauing of the light-round time is physi- 
cally reasonable and likely associated with a complex balance of competing factors. This implies that the strong relationship between light-round time and mixture velocity requires further assessment, in particular for higher flow rates. Realistic gas turbine combustors operate with flow velocities up to $100 \mathrm{~m} / \mathrm{s}$ [1].

To evaluate the effect of fuel properties on ignition and light-round, a series of tests were performed by varying the gaseous fuel employed (methane and ethylene) and $\phi$ of the reactant mixtures. A main focus was comparing mixtures characterised by different thermal power, density ratio, and $\phi$, yet with the same laminar flame speed $\left(S_{L}\right)$. Figure 10a reports light-round time as a function of $S_{L}$. The flow conditions can be retrieved from Table 2 . The mixture velocity was kept constant at $16 \mathrm{~m} / \mathrm{s}$.

The main trend that can be deduced from Fig. 10a is that the light-round time was strongly dependent on the laminar flame speed of the gaseous mixture. Prieur et al. [22] previously reported that increased laminar flame speed was the primary factor contributing to a shorter light-round time in a premixed configuration as compared to a spray configuration. At a fixed bulk velocity and spark longitudinal location, mixtures of methane/air and ethylene/air with varying $\phi$ and matched $S_{L}$ possessed the same $\tau_{L R}$ and behaviour during ignition. For instance, a premixed methane/air mixture with $\phi=0.85$ completed the light-round in the same time as a mixture of ethylene/air with $\phi=0.62$, both mixtures having $S_{L}=0.30 \mathrm{~m} / \mathrm{s}$. When the spark was located downstream, there was always a fairly constant delay in the light-round time. Similarly, in Fig. 9a, a constant time delay was observed when considering light-round time as a function of mixture bulk velocity. Thus, the longitudinal spark location had a consistent effect on the light-round processes, regardless of the other parameters. This is likely due to the necessary upstream propagation of the flame front for the achieving complete ignition of the combustor. The two different configurations (12- and 18-burner) behave similarly, confirming that, in this experimental campaign, there was a negligible influence of inter-burner spacing on the light-round time.

In order to reach high values of $S_{L}$, ethylene/air mixtures with $\phi$ up to 0.9 were tested (star markers in Fig. 10). These cases are of interest because they are thermoacoustically unstable (as reported in Table 2). Thermoacoustic instabilities were observed to develop in the chamber after the ignition transient and did not affect the light-round phenomenon. A detailed study of the link between thermoacoustic instabilities and ignition transience is beyond the scope of the present paper, but will be considered in future works.

The data in Fig. 10a were fitted with a hyperbola $\left(\tau_{L R}\right.$ $\times S_{L}=C$, where $C$ is a constant). Least-squares fitting was used to obtain the constants resulting in $\tau_{L R} \times S_{L} \approx$ $5.2 \mathrm{~m}$ and $\tau_{L R} \times S_{L} \approx 7.3 \mathrm{~m}$, for an initial longitudinal spark location of $x / D=0.5$ and $x / D=5$, respectively. To help understand this trend, the speed of light-round $\left(S_{L R}\right)$ was computed by dividing the distance travelled by the flame arch with $\tau_{L R}$ for each condition:

$$
S_{L R}=\frac{1}{2}\left(\pi \times D_{\text {chamber }}\right) \times \frac{1}{\tau_{L R}}
$$

As the flame formed two branches, it was assumed that the distance travelled by the flame was half of the circumference that connects the bluff body centres in the annular chamber (characterised by a diameter of $D_{\text {chamber }}=170 \mathrm{~mm}$ ). When burning, the gaseous mixture expands due to the difference in density between burned and unburned states. Dilatation increases the flame displacement speed proportionally to this density ratio. As a result, to isolate the speed of propagation of the flame, $S_{L R}$ needs to be divided by the ratio $\rho_{u b} / \rho_{b}$. This speed of propagation is, in first instance, a combination of convection-driven motion of the gaseous mixture and turbulent flame propagation. All the cases reported in Fig. 10a are for the same $U_{m i x}$, therefore the convection-driven part of the flame propagation was the same for all the conditions examined. This speed of propagation was defined as:

$$
S_{\text {prop }}=\left(\frac{\rho_{b}}{\rho_{u b}}\right) \times S_{L R}
$$

Calculated values of $S_{\text {prop }}$ are plotted against $S_{L}$ in Fig. 10b. The data follows a linear trend though the $y$-intercept and the angular coefficient of the linear fits depend on the spark location. The propagation speed appears to be directly proportional to $S_{L}$; specifically, $S_{\text {prop }} \sim 3-4 S_{L}$. Turbulent flame speed can be estimated based on the fractal approach proposed in Refs. [45-47] as:

$$
\frac{S_{T}}{S_{L}} \approx R e_{T}^{1 / 4}
$$

In Eq. 3.2, $\operatorname{Re}_{T}$ is the turbulent Reynolds number, which is defined as $R e_{t}=u^{\prime} L_{t u r b} / v$ [37], where $L_{t u r b}$ is the integral length scale, $u^{\prime}$ the turbulent velocity fluctuations, and $v$ the kinematic viscosity. Considering that the bulk velocity for all these cases is $16 \mathrm{~m} / \mathrm{s}$, and assuming a turbulent intensity of $20 \%$ (i.e. $u^{\prime} \sim 0.20 \times U_{\text {mix }}$ ) $[26,27,31]$, it is possible to estimate $u^{\prime} \sim 3.2 \mathrm{~m} / \mathrm{s}$. Additionally, if $L_{t u r b}$ is assumed to be $\sim 0.15 \mathrm{D}$, the $\operatorname{Re}_{T}$ 


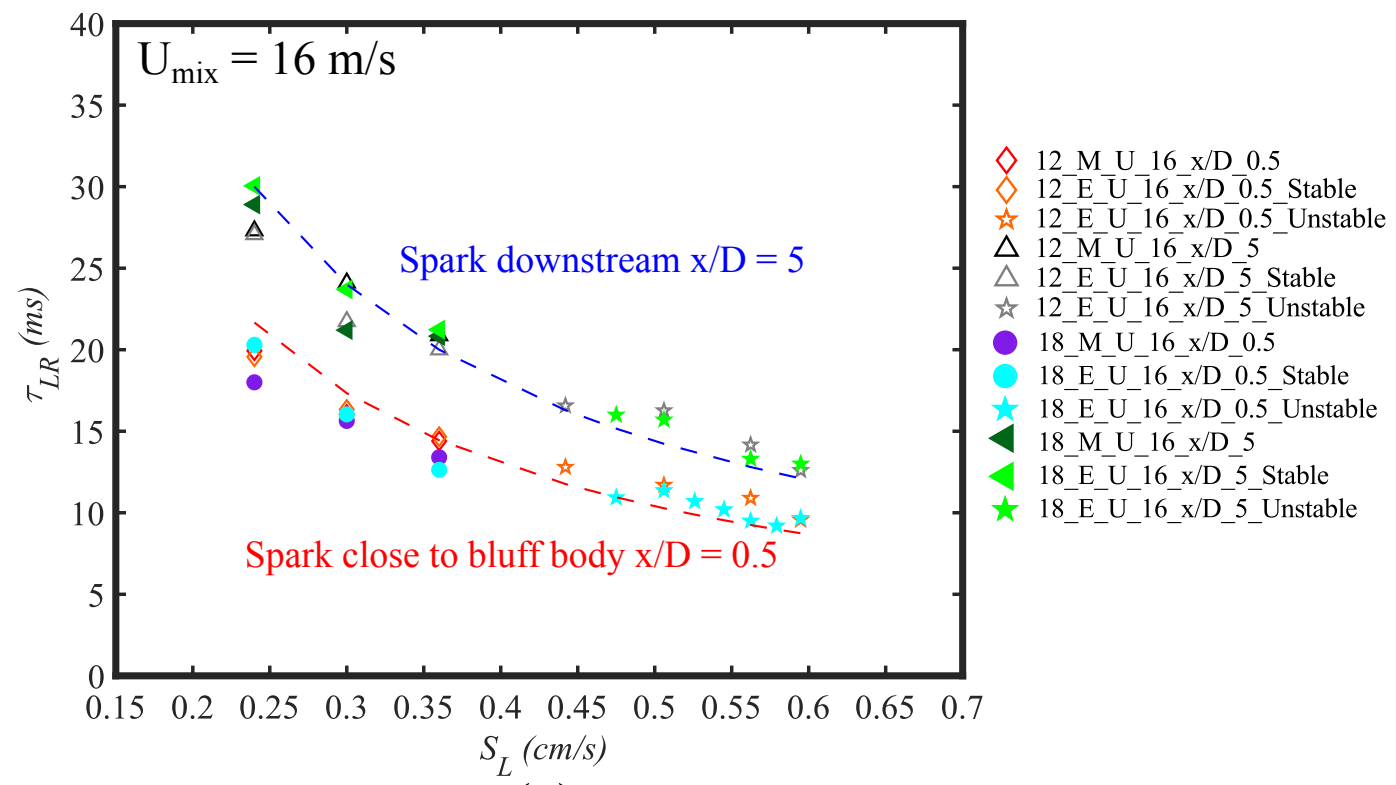

(a)

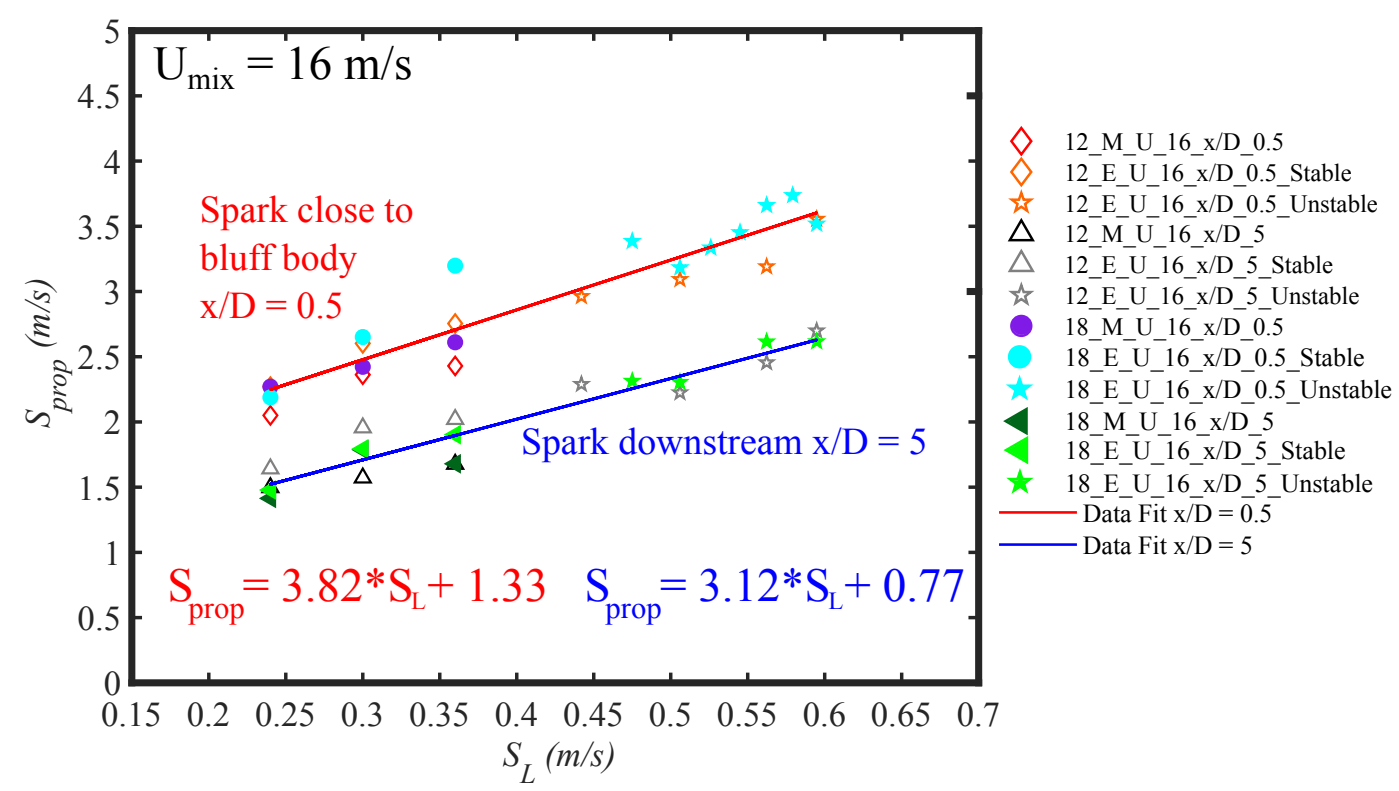

(b)

Figure 10: Plots of light-round time (a) and speed of propagation (b) as a function of $S_{L}$. For all cases $U_{m i x}=16 \mathrm{~m} / \mathrm{s}$. The hollow markers and full markers represent the 12- and 18-burner configurations, respectively. Label is in the form of XX_F_U_V_X/D_L, where XX is the number of burners, $\mathrm{F}$ is the fuel ( $\mathrm{M}$ for methane and $\mathrm{E}$ for ethylene), $\mathrm{V}$ is the bulk velocity and $\mathrm{L}$ the longitudinal spark location. For the tests with ethylene, the addition of unstable refers to mixtures that give rise to thermoacoustic instabilities.

is $\sim 400$. Then from Eq. 3, we obtain $S_{T} \approx 4.47 S_{L}$. The coefficient of proportionality is same order of magnitude as the one of the correlation of $S_{\text {prop }}$ with $S_{L}$ shown in Fig. 10b, with a difference of $\sim 30-40 \%$. In all the cases plotted in Fig. 10 the mixture bulk velocity is the same, which suggests that the convection-driven flame movement is the same for all. Thus, the correlation between $S_{\text {prop }}$ and $S_{L}$ is likely due to the influence of $S_{T}$ on the light-round process. As a result, the calculations above suggest that turbulent flame propagation is 


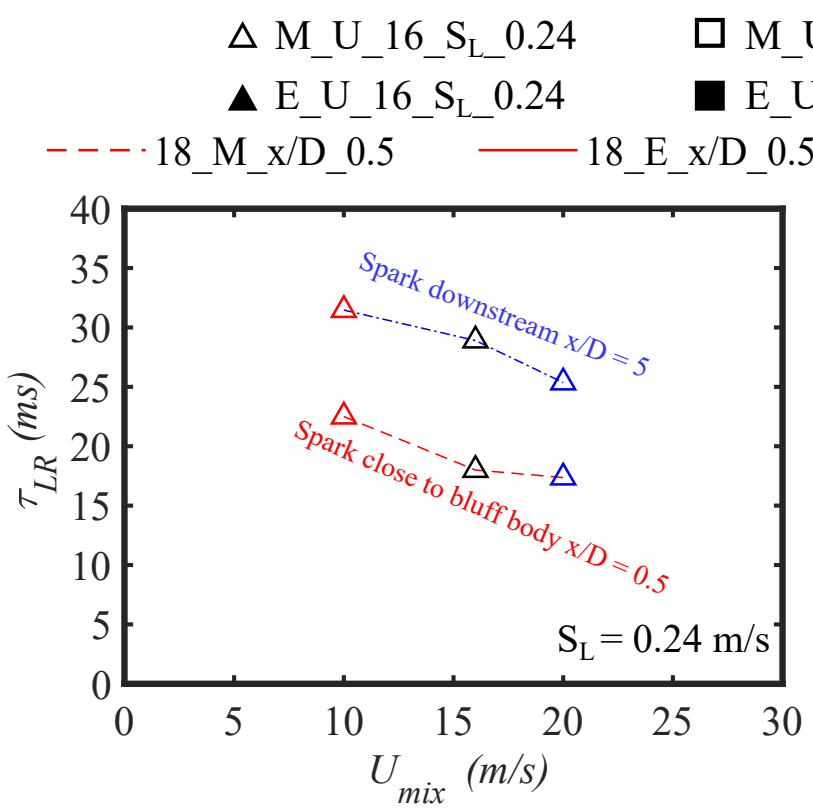

(a)

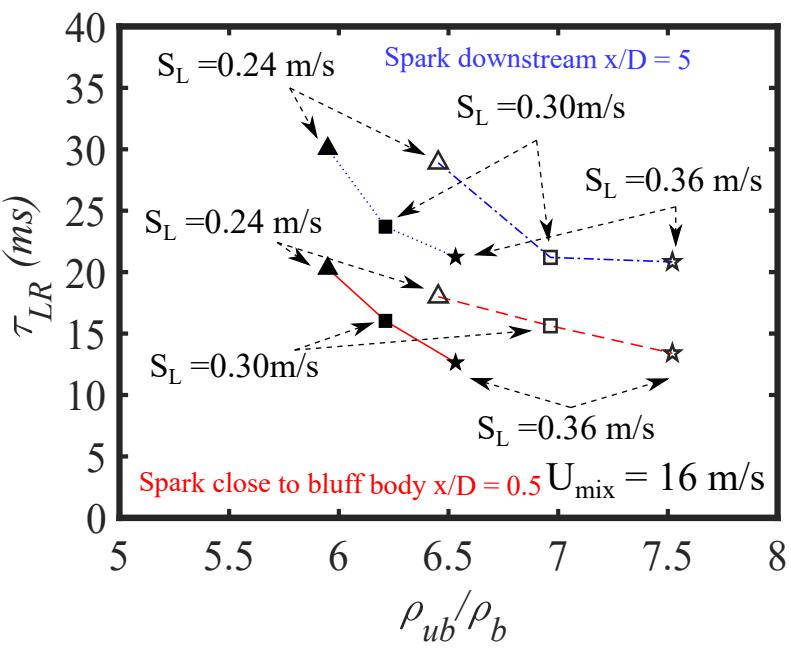

(c)
M_U_16_S $\mathrm{S}_{\mathrm{L} \_} 0.30$

E_U_16_S $\mathrm{S}_{\mathrm{L}} 0.30$
M_U_16_S $\mathrm{L}_{\mathrm{L}} 0.36$

E_U_16_S $\mathrm{L}_{\mathrm{L}} 0.36$

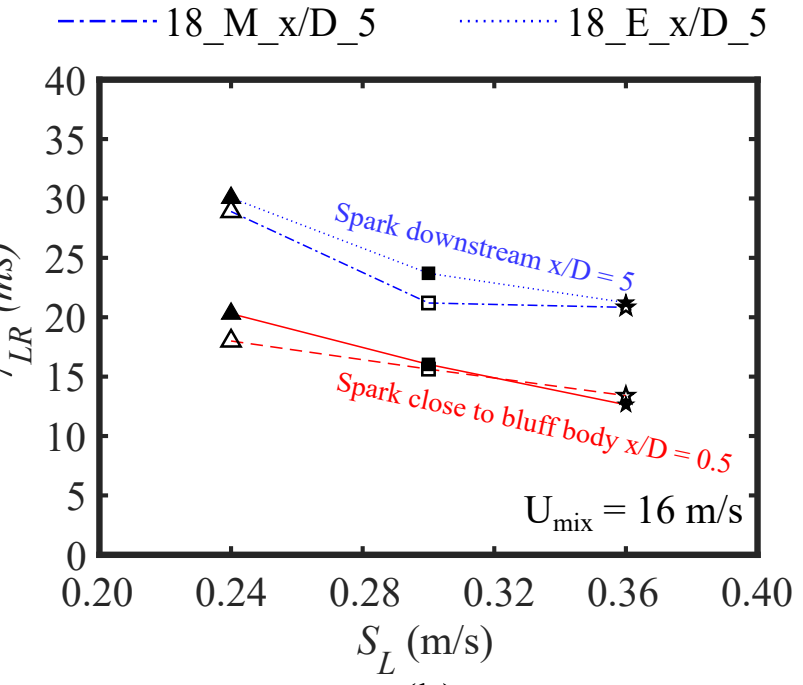

(b)

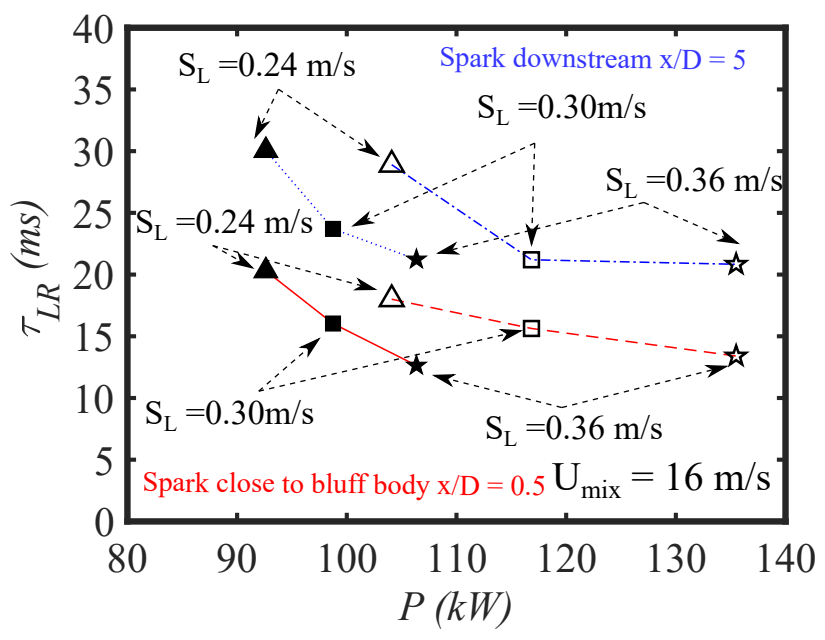

(d)

Figure 11: Light-round time as a function of $U_{\text {mix }}$ (a), $S_{L}$ (b), density ratio between unburned and burned gases $\left(\rho_{u b} / \rho_{b}\right)$ (c) and Thermal Power (d) in the 18-burner configuration. Shape of the markers is related to $S_{L}$, the colour to $U_{\text {mix }}$ and they are hollow or filled whether they refer to mixtures of methane/air or ethylene/air, respectively. In the legend the markers are labelled in the form F_U_XX_S_L_YY, where F is the fuel, XX the $U_{m i x}$ and YY the $S_{L}$. The lines are connectors for the cases with employing same fuel and same spark longitudinal position. Arrows are used in (c) and (d) to clarify which points are from mixtures with the same $S_{L}$.

one of the drivers of the light-round process, additional to the flow convection and the dilatation.

The hypothesis that $S_{L}$ is one of the controlling parameters of the light-round time is reinforced by the results reported in Fig. 11, where $\tau_{L R}$ is plotted against mixture velocity, laminar flame speed, density ratio $\rho_{u b} / \rho_{b}$, and mixture thermal power. The graphs refer to tests performed on the 18-burner configuration, but these conditions are indicative of results from both interburner spacing distances.

To facilitate comparisons between the separate graphs in Fig. 11, the points associated with a particular $S_{L}$ and $U_{\text {mix }}$ are identified by the same marker shape and marker colour, respectively. With a single fuel consid- 
ered, it was reported previously that light-round time decreases with increasing mixture thermal power and density ratio $[23,26]$. However, both these parameters depend on the first instance on mixture composition and this correlation may be a secondary effect of the change of other properties. Figures 11c and 11d show that mixtures characterised by different density ratio and thermal power exhibit similar light-round times. For instance, cases with spark longitudinal location of $x / D=0.5$, in Fig. 11c mixtures methane/air with $\rho_{u b} / \rho_{b} \sim 5.8-6.2-$ 6.5 , ended the light-round process in the same time as mixtures ethylene/air with $\rho_{u b} / \rho_{b} \sim 6.4-7-7.5$, respectively. When sparking at $x / D=5$ the trend was identical yet there was a constant offset in the light-round times. A similar result is reported in Fig. 11d, when plotting $\tau_{L R}$ against the mixture thermal power, where, for instance, $\tau_{L R} \sim 15 \mathrm{~ms}$ for both mixtures of $\sim 98 \mathrm{~kW}$ and $\sim 118 \mathrm{~kW}$.

These trends can be explained when considering Fig. 11b: the cases with matching $\tau_{L R}$ had the same $S_{L}$. Dilatation is linked to the ratio $\rho_{u b} / \rho_{b}$, while turbulent flame propagation depends on the $S_{T}$, which is proportional to $S_{L}$ and $u^{\prime}$ [36-38]. The light-round process is a combination of multiple effects: convection, turbulent flame propagation, and dilatation. As $U_{m i x}$ was kept constant, convection-driven contributions to the flame propagation are the same for all cases. Moreover, $u^{\prime}$ did not change, so turbulent flame propagation depended on $S_{L}$. Thus, as $\tau_{L R}$ was observed to correlate with $S_{L}$ of the mixture, it is probable that turbulent flame propagation overcomes the effect of dilatation in influencing the propagation of the flame. As a result, for a fixed mixture velocity (i.e. similar convection effects), $S_{L}$ is one of the mixture parameters controlling the light-round time. The latter statement sums up one of the main findings of this paper: there is a strong link between $\tau_{L R}$ and $S_{L}$, regardless of the fuel employed.

\section{Conclusions}

This work experimentally investigated the mechanism of ignition in a premixed annular combustor. One emphasis of this work was to study the effect of spark location and laminar flame speed on the light-round process. Four azimuthal locations and two longitudinal position of the spark were considered, along with two gaseous fuels: methane and ethylene.

The effects of bulk velocity, inter-burner spacing, and fuel properties on $\tau_{L R}$ were investigated. Simultaneous high-speed $(10 \mathrm{kHz})$ imaging of $\mathrm{OH}^{*}$ chemiluminescence from the top and the side of the burner allowed for an analysis of the flame propagation pattern. It was observed that the initial kernel evolved into two flame branches that travelled around the chamber following the direction induced by the flow, thus propagating close to the inner wall in the $\mathrm{CW}$ direction and close to outer wall in the ACW direction. The local, swirl-generated tangential flow near the burners was a main driver of the direction of the light-round, inducing a bulk radial tangential flow inside the annular chamber. When the initial spark was located close to the bluff body, the burnerto-burner propagation was similar to that observed in previous works. However, less uniformity was seen in the flame motion, especially in the CW direction. When the spark was positioned at $x / D=5$ (where $D$ is the bluff body diameter), the light-round mechanism was comprised of two patterns that proceeded simultaneously within the chamber: (i) downstream azimuthal propagation of the flame front, (ii) upstream propagation of the flame and stabilisation on the burners, followed by burner-to-burner propagation close to the bluff bodies. The time scale of the upstream flame propagation to ignite the first burners was comparable to the light-round time scale. That is, the light-round process, or azimuthal propagation, began prior to full ignition of the individual burner directly upstream of the spark. This implies that optimisation of the overall light-round time in a real combustor requires prudent consideration of the spark-plug placement. Namely, the aim should be to enhance phases two and three of the ignition transient, that is, the growth and stabilisation of the flame at the first burner.

Increasing mixture bulk velocity lead to a decrease in light-round time, which corroborates results from previous studies. However, $\tau_{L R}$ appeared to reach a plateau for $U_{m i x}>20 \mathrm{~m} / \mathrm{s}$. Such plateauing is likely the consequence of several factors such as the "bending" of $S_{T}$ with increased $u^{\prime}$ and an increase propensity for local extinction at larger $U_{\text {mix }}$. Furthermore, results showed that $\tau_{L R}$ was independent of the initial azimuthal location of the spark. Thus, buoyancy appears to have a negligible effect on the flame front kinematics. In contrast, moving the spark longitudinally along the chamber had an impact on the light-round time, resulting in a constant delay of around $30-40 \%$ in $\tau_{L R}$ when the spark was located at distance of $x / D=5$ from the bluff body compared to igniting close to the burners. The inter-burner distance had a negligible influence on $\tau_{L R}$, as well as the rise of thermoacoustic instabilities, that developed inside the combustor after the anchoring and stabilisation of the flame.

A strong correlation was found between light-round time and laminar burning velocity of the mixture. At a fixed bulk velocity, using different fuels and equivalent 
ratios, giving thermal power and density ratios $\left(\rho_{u b} / \rho_{b}\right)$, but selected to give the same $S_{L}$, the same light-round time was obtained. The propagation speed of the flame front $\left(S_{\text {prop }}\right)$, calculated from the $\tau_{L R}$, was found to be directly proportional to $S_{L}$. Moreover, from an estimate of the turbulent flame speed $\left(S_{T}\right)$, for the conditions examined, a similar correlation was found between $S_{T}$ and $S_{L}$ though the coefficient of proportionality was $\sim 30$ $40 \%$ higher than the one between $S_{\text {prop }}$ and $S_{L}$. These findings suggest that, at a fixed bulk velocity (i.e. similar convection effects), turbulent flame propagation has a first order influence on the light-process, stronger than dilatation. As a result, $S_{L}$ is one of the main parameters controlling the light-round process in addition to flow convection, with a lower order contribution of dilatation.

\section{Acknowledgements}

This work has received funding from the European Union's Horizon 2020 Research and Innovation Programme under the Marie Skłodowska-Curie Grant Agreement No. 765998 as part of project "Annulight." The authors would like to thank Mr. Rohit S. Pathania for his valuable suggestions regarding the operation of the annular combustor.

\section{References}

[1] A. W. Lefebvre, D. R. Ballal, Gas Turbine CombustionAlternative Fuels and Emissions, CRC press, Taylor and Francis group, NY, 2010.

[2] Environment-related Standards and Guidance material on noise, local air quality and climate change, Technical Report, International Civil Aviation Organization (ICAO), 2018.

[3] T. C. Lieuwen, V. Yang, Gas Turbine Emissions, Cambridge University Press, 2017.

[4] I. Glassman, R. A. Yetter, Combustion, Academic Press, 2008.

[5] E. Mastorakos, Forced ignition of turbulent spray flames, Proceedings of the Combustion Institute 36 (2017) 2367-2383.

[6] E. Mastorakos, Ignition of turbulent non-premixed flames, Progress in Energy and Combustion Science 35 (2009) 57-97.

[7] S. F. Ahmed, The probabilistic nature of ignition of turbulent highly-strained lean premixed methane-air flames for lowemission engines, Fuel 134 (2014) 97-106.

[8] M. P. Sitte, E. Bach, J. Kariuki, H. J. Bauer, E. Mastorakos, Simulations and experiments on the ignition probability in turbulent premixed bluff-body flames, Combustion Theory and Modelling 20 (2016) 548-565.

[9] M. Cordier, A. Vandel, G. Cabot, B. Renou, A. M. Boukhalfa, Laser-Induced Spark Ignition of Premixed Confined Swirled Flames, Combustion Science and Technology 185 (2013) 379407.

[10] M. Cordier, A. Vandel, B. Renou, G. Cabot, A. M. Boukhalfa, M. Cazalens, Spark Ignition of Confined Swirled Flames: Experimental and Numerical Investigation, in: Volume 1A: Combustion, Fuels and Emissions, American Society of Mechanical Engineers, 2013, pp. 1-12.
[11] S. F. Ahmed, E. Mastorakos, Spark ignition of lifted turbulent jet flames, Combustion and Flame 146 (2006) 215-231.

[12] S. F. Ahmed, R. Balachandran, T. Marchione, E. Mastorakos, Spark ignition of turbulent nonpremixed bluff-body flames, Combustion and Flame 151 (2007) 366-385.

[13] S. F. Ahmed, R. Balachandran, E. Mastorakos, Measurements of ignition probability in turbulent non-premixed counterflow flames, Proceedings of the Combustion Institute 31 (2007) 1507-1513.

[14] T. Marchione, S. F. Ahmed, E. Mastorakos, Ignition of turbulent swirling n-heptane spray flames using single and multiple sparks, Combustion and Flame 156 (2009) 166-180.

[15] R. W. Read, J. W. Rogerson, S. Hochgreb, Flame imaging of gas-turbine relight, AIAA Journal 48 (2010) 1916-1927.

[16] T. Mosbach, R. Sadanandan, W. Meier, R. Eggels, Experimental Analysis of Altitude Relight Under Realistic Conditions Using Laser and High-Speed Video Techniques, volume 2: Combustion, Fuels and Emissions, Parts A and B of Turbo Expo: Power for Land, Sea, and Air, pp. 523-532.

[17] D. Barré, L. Esclapez, M. Cordier, E. Riber, B. Cuenot, G. Staffelbach, B. Renou, A. Vandel, L. Y. Gicquel, G. Cabot, Flame propagation in aeronautical swirled multi-burners: Experimental and numerical investigation, Combustion and Flame 161 (2014) 2387-2405.

[18] J. Marrero-Santiago, A. Verdier, A. Vandel, G. Cabot, A. M. Boukhalfa, B. Renou, Effect of injector spacing in the lightaround ignition efficiency and mechanisms in a linear swirled spray burner, Heat and Mass Transfer 55 (2019) 1871-1885.

[19] E. Machover, E. Mastorakos, Experimental and numerical investigation on spark ignition of linearly arranged non-premixed swirling burners, Combustion Science and Technology 189 (2017) 1326-1353.

[20] M. Boileau, G. Staffelbach, B. Cuenot, T. Poinsot, C. Bérat, LES of an ignition sequence in a gas turbine engine, Combustion and Flame 154 (2008) 2-22.

[21] E. Machover, E. Mastorakos, Spark ignition of annular nonpremixed combustors, Experimental Thermal and Fluid Science 73 (2016) 64-70.

[22] K. Prieur, D. Durox, J. Beaunier, T. Schuller, S. Candel, Ignition dynamics in an annular combustor for liquid spray and premixed gaseous injection, Proceedings of the Combustion Institute 36 (2017) 3717-3724.

[23] T. Lancien, K. Prieur, D. Durox, S. Candel, R. Vicquelin, Large Eddy Simulation of Light-Round in an Annular Combustor With Liquid Spray Injection and Comparison With Experiments, Journal of Engineering for Gas Turbines and Power 140 (2017) 021504.

[24] K. Prieur, D. Durox, G. Vignat, T. Schuller, S. Candel, Flame and Spray Dynamics During the Light-Round Process in an Annular System Equipped With Multiple Swirl Spray Injectors, ASME. Turbo Expo: Power for Land, Sea, and Air, Volume 4B: Combustion, Fuels, and Emissions 141 (2018).

[25] S. Puggelli, T. Lancien, K. Prieur, D. Durox, S. Candel, R. Vicquelin, Impact of Wall Temperature in Large Eddy Simulation of Light-Round in an Annular Liquid Fueled Combustor and Assessment of Wall Models, in: Proceedings of the ASME Turbo Expo 2019: Turbomachinery Technical Conference and Exposition, volume 4B: Combustion, Fuels, and Emissions.

[26] J. F. Bourgouin, D. Durox, T. Schuller, J. Beaunier, S. Candel, Ignition dynamics of an annular combustor equipped with multiple swirling injectors, Combustion and Flame 160 (2013) 13981413.

[27] E. Machover, E. Mastorakos, Experimental investigation on spark ignition of annular premixed combustors, Combustion and Flame 178 (2017) 148-157. 
[28] Y. Xia, C. Linghu, Y. Zheng, C. Ye, C. Ma, H. Ge, G. Wang, Experimental Investigation of the Flame Front Propagation Characteristic During Light-round Ignition in an Annular Combustor, Flow, Turbulence and Combustion (2019).

[29] M. Philip, M. Boileau, R. Vicquelin, E. Riber, T. Schmitt, B. Cuenot, D. Durox, S. Candel, Large eddy simulations of the ignition sequence of an annular multiple-injector combustor, Proceedings of the Combustion Institute 35 (2015) 3159 - 3166.

[30] R. Ciardiello, R. S. Pathania, P. M. Allison, P. M. de Oliveira, E. Mastorakos, Ignition probability and lean ignition behaviour of a swirled premixed bluff body stabilised annular combustor, in: ASME turbo expo 2020, London, 22-26 June 2020. Accepted for presentation.

[31] N. A. Worth, J. R. Dawson, Self-excited circumferential instabilities in a model annular gas turbine combustor: Global flame dynamics, Proceedings of the Combustion Institute 34 (2013) 3127-3134.

[32] N. A. Worth, J. R. Dawson, Modal dynamics of self-excited azimuthal instabilities in an annular combustion chamber, Combustion and Flame 160 (2013) 2476-2489.

[33] P. M. Allison, E. Mastorakos, Forced Response of Flames in a Bluff-Body Stabilized Annular Combustor, in: 55th AIAA Aerospace Sciences Meeting, 2017, pp. 1-12.

[34] R. Ciardiello, A. W. Skiba, R. L. Gordon, E. Mastorakos, Experimental assessment of the lean blow-off in a fully premixed annular combustor, Experimental Thermal and Fluid Science 112 (2020) 109994. In press.

[35] A. G. Gaydon, H. G. Wolfhard, Flames, their structure, radiation, and temperature, Halsted Press, 1979.

[36] J. F. Driscoll, Turbulent premixed combustion: Flamelet structure and its effect on turbulent burning velocities, Progress in Energy and Combustion Science 34 (2008) 91 - 134.

[37] N. Peters, Turbulent Combustion, Cambridge University Press, 2000.

[38] A. Lipatnikov, J. Chomiak, Turbulent flame speed and thickness: phenomenology, evaluation, and application in multidimensional simulations, Progress in Energy and Combustion Science 28 (2002) 1 - 74.

[39] J. F. Driscoll, J. H. Chen, A. W. Skiba, C. D. Carter, E. R. Hawkes, H. Wang, Premixed flames subjected to extreme turbulence: Some questions and recent answers, Progress in Energy and Combustion Science 76 (2020) 100802.

[40] G. Nivarti, S. Cant, Direct numerical simulation of the bending effect in turbulent premixed flames, Proceedings of the Combustion Institute 36 (2017) 1903 - 1910.

[41] J. Kariuki, J. R. Dawson, E. Mastorakos, Measurements in turbulent premixed bluff body flames close to blow-off, Combustion and Flame 159 (2012) 2589-2607.

[42] W. Y. Kwong, A. M. Steinberg, Blowoff and reattachment dynamics of a linear multi-nozzle combustor, Journal of Engineering for Gas Turbines and Power 141 (2018) 1-9.

[43] S. Chaudhuri, S. Kostka, M. W. Renfro, B. M. Cetegen, Blowoff dynamics of bluff body stabilized turbulent premixed flames, Combustion and Flame 157 (2010) 790 - 802.

[44] B. R. Chowdhury], B. M. Cetegen, Effects of free stream flow turbulence on blowoff characteristics of bluff-body stabilized premixed flames, Combustion and Flame 190 (2018) 302 - 316.

[45] G. Andrews, D. Bradley, S. Lwakabamba, Turbulence and turbulent flame propagation-a critical appraisal, Combustion and Flame 24 (1975) 285 - 304.

[46] F. Gouldin, An application of fractals to modeling premixed turbulent flames, Combustion and Flame 68 (1987) 249 - 266.

[47] R. S. Kant, E. Mastorakos, An introduction to turbulent reacting flows, Imperial college press, 2007. 